\title{
UNCERTAINTIES IN RISK ASSESSMENTS AT USDOE FACILITIES
}

\author{
L.D. Hamilton, S. Holtzman, A.F. Meinhold, S.C. Morris, M.D. Rowe
}

January 1994

\author{
Prepared for: \\ Office of Environmental Restoration and Waste Management \\ Office of Technology Development \\ United States Department of Energy
}
Biomedical and Environmental Assessment Group
Analytical Sciences Division
Department of Applied Science
Brookhaven National Laboratory
Upton, NY 11973

Work performed under the auspices of the U.S. Department of Energy by Brookhaven National Laboratory under Contraci No. DE-AC.02-76CH00016 


\section{ACKNOWLEDGMENTS}

This study was funded by the United States Department of Energy, Office of Environmental Restoration and Waste Management, Office of Technology Development. The Project Officer for the study was Mr. Michael Barainca. This study was performed by the Biomedical and Environmental Assessment Group, Brookhaven National Laboratory (BNL). The principal investigator for the work was Dr. L. D. Hamilton. 


\section{DISCLAIMER}

This report was prepared as an account of work sponsored by an agency of the United States Government. Neither the United States Government nor any agency thereof, nor any of their employees, make any warranty, express or implied, or assumes any legal liability or responsibility for the accuracy, completeness, or usefulness of any information, apparatus, product, or process disclosed, or represents that its use would not infringe privately owned rights. Reference herein to any specific commercial product, process, or service by trade name, trademark, manufacturer, or otherwise does not necessarily constitute or imply its endorsement, recommendation, or favoring by the United States Government or any agency thereof. The views and opinions of authors expressed herein do not necessarily state or reflect those of the United States Government or any agency thereof. 


\section{DISCLAIMER}

Portions of this document may be illegible in electronic image products. Images are produced from the best available original document. 


\section{Table of Contents}

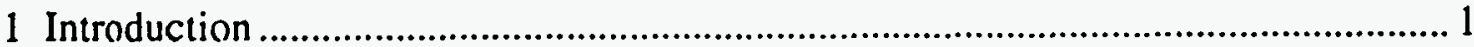

1.1. Uncertainties in Risk Assessments for USDOE Facilities ...................................

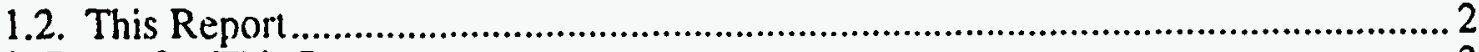

2 Bases for This Report ......................................................................................... 3

2.1 Brief Review of the Pilot Study ........................................................................... 3

2.2. Brief Review of the Lessons Leamed Report ..................................................... 6

2.3. Workshop on Uncertainty ............................................................................. 7

2.4. Symposium on Uncertainty ...................................................................... 8

2.5. Keeping Up-to-date on Uncertainty Analysis ..................................................... 8

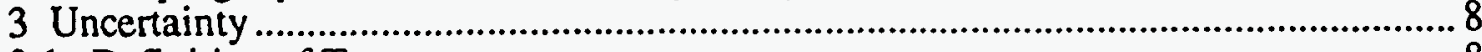

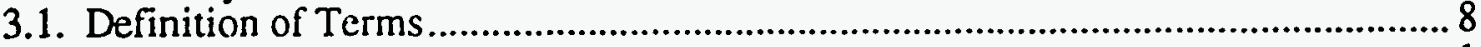

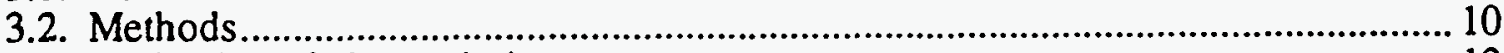

4 Prioritization of Uncertainties ........................................................................... 13

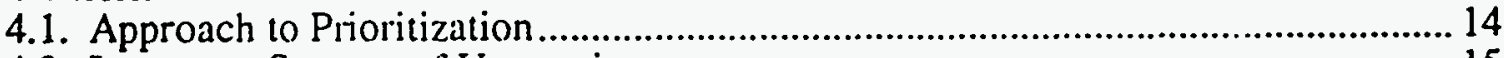

4.2. Important Sources of Uncertainty .............................................................. 15

4.3. Cost-effectiveness of Uncertainty Reduction or Replacing Uncertainty with

Knowledge.

5 Major Uncertaintics in Risk Assessment for USDOE Facilities............................... 17

5.1. Source Terms and Site-Specific Information ..................................................... 17

5.2. Identification of Scenarios and Receptors ..................................................... 18

5.3. Environmental Transport ................................................................................... 20

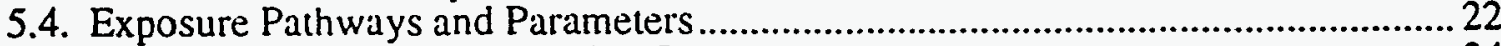

5.5. Dose-response Models and Risk Factors ............................................................ 24

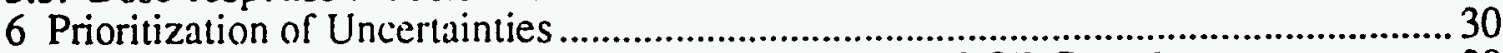

6.1. Most Important Sources of Uncertainty Across the DOE Complex .......................... 30

6.2. Recommended Research on Uncertainties that DOE Can Reduce

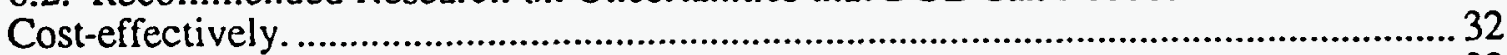

7 Summary and Conclusions on Reduction of Uncertainty ......................................... 33

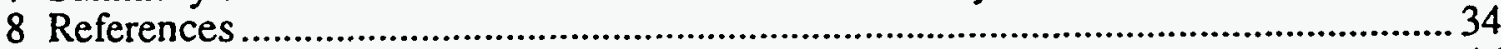

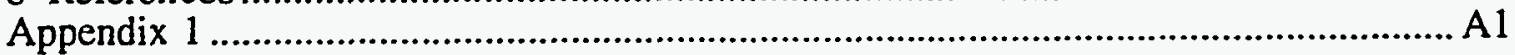




\section{Introduction}

The United States Department of Energy (USDOE) has embarked on an ambitious program to remediate environmental contamination at its facilities. Decisions concerning cleanup goals, choices among cleanup technologies, and funding prioritization should be largely risk-based. Risk assessments will be used more extensively by the USDOE in the future. USDOE needs to develop and refine risk assessment methods and fund research to reduce major sources of uncertainty in risk assessments at USDOE facilities.

The terms 'risk assessment' and 'risk management' are frequently confused. The National Research Council (1983) and the United States Environmental Protection Agency (USEPA, 1991a) described risk assessment as a scientific process that contributes to risk management.

Risk assessment is the process of collecting, analyzing and integrating data and information to identify hazards, assess exposures and dose responses, and characterize risks. Risk characterization must include a clear presentation of "...the most significant data and uncertainties..." in an assessment. Significant data and uncertainties are "...those that define and explain the main risk conclusions" (Habicht, 1992).

Risk management integrates risk assessment information with other considerations, such as risk perceptions, socio-economic and political factors, and statutes, to make and justify decisions.

Risk assessments, as scientific processes, should be made independently of the other aspects of risk management (USEPA, 1991a), but current methods for assessing health risks are based on conservative regulatory principles, causing unnecessary public concern and misallocation of funds for remediation. Conservatism in assessments arises from the interactions of single values (usually high; e.g., combining upper $95 \%$ confidence limit values of several parameters in a calculation) in worst-case scenarios (e.g., a hypothetical maximally exposed individual). This approach is used for regulation because it insures protection against the worst possible conditions, but it is not useful for comparing different risks because it provides inadequate information about expected values, distributions and uncertainties.

\subsection{Uncertainties in Risk Assessments for USDOE Facilities}

Uncertainties in risk assessment are important to risk management decisions. Shevenell and Hoffman (1993) recently described how risk assessments using conservative assumptions, in the absence of uncertainty analyses, yield unreliable ranking of waste management areas. Descriptions of uncertainties may indicate the quality of the information in a risk assessment that is available to the decision maker. The overall uncertainty associated with a risk estimate can tell a risk manager if a risk is likely to exceed a predetermined acceptable 
level. Clear expression of the uncertainties in the steps in the risk assessment can guide a risk manager's decision on removal of the major sources of risk.

A number of uncertainties hamper risk assessments at USDOE facilities. Seviral factors contribute to these uncertainties, including: limitations in the data that characterize sites and source terms; uncertainties in transport model formulat on and physical parameters used as input to the models (e.g., diffusion coefficients); exposure parameters; and dose-response relationships. Some of these uncertainties are inherent in the analysis of risk (for example, the variability in the characteristics of a population or the uncertainty associated with projecting future population growth), while others are a result of a lack of knowledge or data. Some of the factors contributing to the uncertainty in final risk estimates are also more important than others.

\subsection{This Report}

The purpose of this report is to quantify or qualify uncertainties in risk assessments at USDOE facilities. This work will benefit USDOE directly by identifying uncertainties in risk assessments at USDOE facilities that: (1) are important in the overall uncertainty of the final risk estimates; and (2) can be addressed directly and cost-effectively by USDOE.

The results of this task can be used to prioritize research supporting risk assessment at USDOE facilities to gain maximum benefit for research dollars spent, and to guide risk assessors in dealing reasonably with uncertainty.

This work will be immediately useful to USDOE in planning its research program. Potential users of this work include National Laboratories, outside contractors and other groups that do risk assessments at USDOE facilities.

This work was based in part on lessons learned from risk assessments in a pilot study recently completed by the Biomedical and Environmental Assessment Group, Brookhaven National Laboratory, and the Health and Ecological Assessment Division, Lawrence Livermore National Laboratory (Hamilton et al., 1993a, b; Daniels et al., 1993; Layton et al., 1993). These assessments and some specific lessons learned from the analyses are described in Section 2 of this report. Other bases for the analyses and conclusions presented in this report include a workshop on uncertainty held at Brookhaven National Laboratory (Section 2.3), current literature and recent scientific meetings.

Section 3 summarizes the terms and methods currently used in uncertainty analysis. Section 4 summarizes sources of uncertainty in risk assessments, and describes the definitions and procedure used to quantify or qualify these uncertainties to guide research priorities. Section 5 describes major sources of uncertainty in realistic risk assessments for USDOE facilities, as exemplified by the pilot study. Section 6 describes the prioritization of uncertainties, and recommends cost-effective research that can be undertaken by USDOE. Section 7 summarizes this report and its conclusions on research that should be supported by USDOE. 


\section{Bases for This Report}

Uncertainty was specifically identified as a major area of concerr. in a previous report "Lessons learned: needs for improving human health risk assessment at USDOE sites" (Hamilton et al., 1993c). That report was based o a pilot study consisting of two health risk assessments at each of three USDCIE sites, as described in the following sections. The current report describes, the results of investigations to identify major sources of uncertainty in risk assessments at USDOE sites, and to prioritize uncertainties that could be reduced cost-effectively with support from USDOE.

\subsection{Brief Review of the Pilot Study}

A pilot study was recently completed in which health risks were assessed for problems at three USDOE sites:

(1) the Savannah River Site (SRS - Hamilton et al., 1993a);

(2) the Fernald Environmental Management Project (FEMP - Hamilton et al., 1993b); and

(3) the Nevada Test Site (NTS - Daniels et al., 1993; Layton et al., 1993).

The pilot study aimed to:

(1) demonstrate and develop methods for realistic risk assessments;

(2) produce usable and credible estimates for the problems studied; and

(3) begin to change the way risk assessments are done at USDOE facilities.

\subsubsection{Approach}

The Pilot Study demonstrated a realistic and objective approach to risk assessment, using distributions of parameter values, and uncertainty bounds on the distributions, to obtain probabilistic estimates of health risks. The definition of a realistic and objective risk assessment is one that:

(1) Avoids unrealistic and conservative exposure scenarios by focusing on reasonable and sensible scenarios;

(2) Replaces generic or inappropriate default assumptions with site-specific data or assumptions;

(3) Characterizes uncertainties in parameters explicitly, and does not depend on conservative assumptions;

(4) Uses site-specific transport and exposure models, and depends on monitoring data for model calibration or input parameters;

(5) Uses the latest scientific information in describing dose-response relationships;

(6) Acknowledges that situations with little data available to describe source terms or exposure routes cannot be assessed in a realistic way without additional data collection. These situations can be addressed credibly and practically in screening level assessments.

(7) Addresses uncertainty and variability. 
Where possible, these assessments employed realistic distributions of parameter values in place of conservative default values to yield probabilistic predictions of risks and their associated uncertainties.

\subsubsection{The Savannah River Site}

Assessments for the SRS were made for releases of tritium and $137 \mathrm{Cs}$ from the SRS into the Savannah River. Although reactor operations were shut down at the SRS in 1989, the site continues to release liquid wastes into the Savannah River, either by direct discharges into onsite surface waters, or by ground water transport into surface waters from waste facilities. Existing state mandates will cause the liquid waste streams from future operations to go directly into surface waters. Two drinking water processing plants take water from the river approximately $160 \mathrm{~km}$ downriver from the SRS. The domestic populations supplied by these facilities are expected to increase from 57,000 , in 1990 , to 367,000 , by the year 2000 . Potential incremental risks of cancer fatality to individuals and each population were analyzed for either no further reactor operations or resumption of operation of one specific reactor.

The major radioactive component of the releases (approximately 99\%) is tritium. Data from 1954 to 1989 were used to develop an empirical model that predicts annual releases of tritium to the Savannah River, and tritium concentrations in the water at the drinking water plants. Groundwater migration from previous releases to waste facilities was predicted to be a component of the source terms until the year 2004. The major exposure pathways for the potentially exposed (receptor) populations were ingestion of tap water ( $85 \%$ ), and inhalation of water vapor while bathing in the home (15\%). Exposures from other pathways were at least one order of magnitude lower. For the year of maximal exposure, the upper 95th percentile level of incremental individual lifetime risk of cancer death was $8 \times$ $10^{-7}$. For lifetime exposures to tritium releases from the SRS, the lifetime risks of cancer death in either total receptor population were always less than one.

Less than $600 \mathrm{Ci}$ of $137 \mathrm{Cs}$ was released to onsite streams from SRS operations since 1954, most of which has bound to sediments of the stream beds of the onsite tributaries. Less than half this amount remains because of radioactive decay, and solution and suspension discharge to the Savannah River. The estimated rate of discharge to the river, less than $0.5 \mathrm{Ci}$ per year, was predicted to continue into the first quarter of the twenty-second century, with or without further operations at the SRS. The major exposure pathways for the receptor populations described above were ingestion of finfish taken from the river, and ingestion of tap water. Exposure from fish ingestion averaged 9 to 18 times greater than that from drinking water, because of bioconcentration in fish and removal of $137 \mathrm{Cs}$ by the water purification plants. The upper 95 th percentile level of incremental individual lifetime risk of cancer death was less than $10^{-8}$. The lifetime risks of cancer death were always less than one for lifetime exposures of either total receptor population to $137 \mathrm{C}$ s releases from the SRS. 


\subsubsection{The Fernald Environmental Management Project}

Radon emissions from the K-65 waste silos and offsite contamination of ground water with uranium were studied at the FEMP facility in Fernald, Ohio.

Waste from the processing of pitchblende ore is stored in the K-65 silos at the FEMP. Radium-226 in the waste decays to radon gas, which escapes to the outside atmosphere. The concern is tor lung cancer risks from radon exposure of nearby residents. Monitoring data and a Gaussian plume transport model were used to develop a source term and predict exposure and risk to fenceline residents, residents within 1 and 5 miles of the silos, and residents of Hamilton and Cincinnati, Ohio. Two release scenarios were studied: the routine release of radon from the silos and an accidental loss of one silo dome integrity. Exposure parameters and risk factors were described as distributions. Risks associated with natural background radon concentrations were also estimated.

Exposure to radon associated with the K-65 silos was estimated to result in individual lifetime risks greater than $1 \times 10^{-4}$ only for indoor workers at the facility (mean: $4.3 \times 10^{-4}$ ) and fenceline residents (median: $1.8 \times 10^{-4}$ ) under the routine release scenario. Population risks associated with the routine and accidental release scenarios were less than 1.0 cancer per lifetime in each identified receptor population. Individual and population risks associated with background radon concentrations (median individual risk: $7.3 \times 10^{-3}$ ) were 1 to 4 orders of magnitude larger than the risks associated with radon from the silos.

Historical releases of uranium at the FEMP produced a plume of uranium in ground water south of the facility. The concern is for toxic effects and an increased risk of cancer to people using contaminated ground water. Two scenarios were considered: 1) a continuing source of uranium; and 2) no additional (stop) source. IT Corporation used a calibrated three-dimensional groundwater transport model to predict the plumes. Exposures and risks were estimated (for the future 70 years) for people using: existing residential wells; potential wells located along the center of the developing plume; and for all possible future well locations in the impacted area. Exposure routes included in the assessment were intakes by ingestion of water, homegrown food, and homeproduced milk. Distributions of the intake rates were derived from published data.

The probability of a toxic effect was defined as the probability of kidney uranium concentration exceeding a threshold. A distribution of the threshold value for effects in the kidney was developed, based on a pharmacokinetic model. The cancer risk assessment was based on annual limits on intake (ALI) values published by the International Commission of Radiological Protection (ICRP), modified to reflect a distribution of gut uptake factors and a dose committed over a 70-year lifetime.

In both the stop and continue source scenarios, no toxic effects were predicted for people using water from any individual well. An assessment using additional incorporated model uncertainties predicted a probability of $4 \times 10-6$ for toxic effects in individuals, from any well, south of the FEMP in the next 70 years. 
All estimated cancer risks were small. The largest predicted individual lifetime risk was for a specific residential well $\left(1.3 \times 10^{-5}\right)$. The predicted individual lifetime risks of cancer fa'ality for wells located anywhere south of the facility were small (always less t $12{ }^{2} 2.2 \times 10.5$ ). Predicted risks for both the stop and continue source scenarics were similar because most exposure is from uranium discharged before 1989 .

\subsubsection{The Nevada Test Site}

The two problems selected for examination at the NTS were potential soil-based exposures to plutonium dispersed by above-ground tests (conducted in the late 1950 s and early 1960s), and potential exposures to ground water contaminated by radionuclides produced by underground tests of nuclear weapons devices (conducted since late 1962).

In the assessment of plutonium contamination, three basic exposure scenarios were defined that could bring individuals in contact with 239,240 Pu at the sites: (1) a resident living in a subdivision; (2) a resident farmer; and (3) a worker at a commercial facility - all located at a test site. The predicted cancer risks for the resident farmer were more than a factor of three times higher than the suburban resident at the median risk level, and about a factor of ten greater than the reference worker at a commercial facility. At 100 years from the present, the 5, 50 , and 95th percentile cancer risks for the resident farmer at the most contaminated site were $4 \times 10^{-6}, 6 \times 10^{-5}$, and $5 \times 10^{-4}$, respectively.

The potential cancer risks for a member of the public from drinking contaminated ground water were determined either at one location on the NTS (assuming loss of institutional control after 100 years) or at one offsite location (considering groundwater migration). Maximum potential excess lifetime risks of cancer mortality estimated for offsite individuals ranged from $7 \times 10^{-7}$ to $1 \times 10^{-5}$. For those at the onsite location the risks ranged from $3 \times 10^{-3}$ to $2 \times 10^{-2}$. Both the offsite and onsite estimates of risk were dominated by lifetime doses from tritium.

For the assessment of $\mathrm{Pu}$ in surface soil, the principal sources of uncertainty in the estimated risks were population mobility, the relationship between indoor and outdoor contaminant levels, and the dose and risk factors for bone, liver, and lung. The critical uncertainty for the assessment of radionuclides in ground water is the distribution of their concentrations today under the entire NTS.

\subsection{Brief Review of the Lessons Learned Report}

The report, "Lessons Learned: Needs For Improving Human Health Risk Assessment At USDOE Sites" (Hamilton et al., 1993c), used the pilot study assessments to identify and guide research to:

(1) eliminate gaps in data; and

(2) address methods needed for risk assessment at USDOE facilities. 
Specifically recommended topics for short-term research to improve risk estimates at USDOE facilities included:

(1) selection of distributions of parameters for Monte Carlo simulations;

(2) as:sessments of risk reductions associated with specific remediation approaches;

(3) reanalyses of the 1984 and 1989 USDA data bases on food intakes, for use in risk assessment;

(4) effects of processing and cooking on contaminant levels in foods;

(5) estimation of background concentrations of contaminants in the environment and foods associated with USDOE facilities;

(6) methods for handling groundwater plumes associated with DOE facilities;

(7) methods for analyzing risks from less than lifetime exposures to carcinogens;

(8) improved estimates of biotransfer factors;

(9) determination of factors that affect frequency and duration of exposure; and

(10) risk characterization for plutonium and noble gasses.

That report specifically recommended initiation of a systematic approach to identify, prioritize, and reduce sources of uncertainty in risk assessments at DOE facilities.

\subsection{Workshop on Uncertainty}

The Biomedical and Environmental Assessment Group (BEAG) at Brookhaven National Laboratory hosted a workshop on August 4, 1993 (Appendix 1). The purpose of the workshop was to determine the major uncertainties associated with risk assessments at U.S. Department of Energy Facilities, and to explore methods for describing and reducing these uncertainties.

The participants in the workshop (Appendix 1) included a variety of experts from federal agencies, such as USEPA and USDOE, national laboratories, academia, and the private sector. Many of these experts are distinguished scientists with extensive experience in identifying and quantitating uncertainties in risk assessment, and developing methods that are useful for expressing and reducing uncertainties.

Sources of uncertainty were identified, and categorized as to their site-specific, regional, national or universal nature. There was general agreement that a screening level assessment should be done to identify the important uncertainties that contribute most to the distribution of risk. There is a need to identify parameters that are correlated, and effects of the correlations on uncertainties. Analytical methods were suggested to accomplish these goals. Advice was sought from the experts on unifying or simplifying the terminology associated with uncertainty analysis. 


\subsection{Symposium on Uncertainty}

At the annual meeting of the Society for Risk Analysis (Savannah, GA, December, 1993) approximately 25 presentations either had the word uncertainty in their titles or were concerned with uncertainty, including a session specifically devoted to uncertainty analysis. More than 500 participants at this meeting included representatives from federal agencies (USEPA, USFDA, USDA, US Fish and Wildlife Service, USDOE), academia, and the private sector. Personal contact with many of the attendees provided additional information and sources of information on uncertainties in risk assessments.

\subsection{Keeping Up-to-date on Uncertainty Analysis}

Although specific federal agencies may bear major responsibility for collecting data and information, the appropriate application of the information for the problem at hand is the responsibility of the individual analyst or analytical group. Risk analysis is an iterative process, in which uncertainty may be reduced by additional data and new approaches. Therefore, it is imperative that analysts keep up to date with new developments in the field, by obtaining information from the latest literature, attendance at scientific meetings, and direct contact with experts. This report is partly based on a synthesis of information gained from: the Pilot Study; the Workshop on Uncertainty; the meeting of the Society for Risk Analysis; recent publications in the open literature; and other risk assessment studies performed by BEAG (BNL) and HEAD (LLNL).

\section{Uncertainty}

\subsection{Definition of Terms}

Although various sources present apparently different definitions and classification schemes for factors affecting the quality of risk estimates (Appendix 1), much of the difference reflects word choices. In some cases, different sources present opposite definitions of the same words (e.g., "uncertainty" and "variability" in Morgan and Henrion, 1990 and USEPA, 1992a). Some of this confusion arises from historical uses of terms from other contexts that are conflicting when combined in the same context. Uncertainty arises from combinations of heterogeneity (variability), measurement error, and lack of knowledge (Figure 1). The following discussion outlines the working set of definitions used in this report. 
Figure 1. Uncertainty arises from combinations of heterogeneity, measurement error, and lack of knowledge.

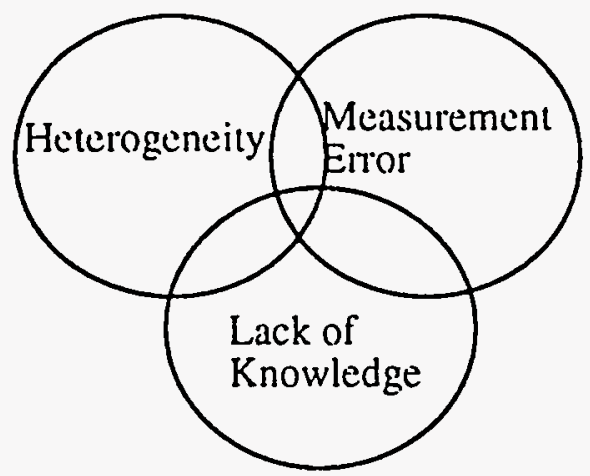

Parameter is used in this report as a component (= property or variable) that can be characterized either quantitatively or qualitatively.

Heterogeneity is the variability within a parameter. For example, it is relatively easy to determine the amount of water that an individual drinks daily, but the amount will vary from day to day for the individual, and among individuals in a population.

Measurement error arises from inadequacy of sampling, sampling biases, errors in the measurements, and imprecision.

Lack of knowledge can involve parameters that are quantitatively expressed, and components of a risk assessment that do not have numerical values per se. The less one knows about a parameter, the greater the uncertainty. Major sources of uncertainty include inadequate knowledge of physical processes, such as environmental transport mechanisms, and gaps in qualitative knowledge, such as future land-use scenarios (Appendix 1). Parameters and their ranges of values can be profoundly affected by choices among these components of a risk assessment, in turn affecting the overall uncertainties in the risk estimates.

Most parameters used in risk assessments contain elements of heterogeneity, measurement error, and lack of knowledge. Heterogeneity is a property of the physical and natural environment, while measurement error and lack of knowledge contribute to estimates of uncertainty that describe the range of values in a heterogeneous parameter. Therefore, measurement error and lack of knowledge are often treated as a category that is separate from heterogeneity (Appendix Table 1). 


\subsection{Methods}

\subsubsection{Sensitivity and Uncertainty Analyses}

Sensitivity analysis and uncertainty analysis are different processes. Sensitivity analysis is used to determine which parameters are the most important contributors to the magnitude of an overall risk estimate. These analyses compare all parameters in an assessment for the overall effects of a specific change (e.g., a 20\% variation) in each parameter (Morgan and Henrion, 1990). The analyses may or may not be independent of the uncertainties of the parameters.

Uncertainty analyses (sensitivity to quantity range changes - Rish, 1988) provide estimations of the actual contribution of uncertainty associated with each variable to the overall uncertainly in a risk estimate. These analyses determine the effect of uncertainty of each parameter on the result. A sensitivity analysis can be done as part of an uncertainty analysis to identify the parameters that contribute the most to the variance of the final risk estimates. The analysis quantifies sensitivity of uncertainty of a risk estimate to a changed range or assumed type of distribution of a single variable.

\subsubsection{Monte Carlo Simulation Approach}

Many risk assessments at USDOE facilities are made according to USEPA guidelines; the specifics of the analyses are usually dictated by the USEPA regional office responsible for the facility. A baseline exposure and risk assessment is conducted to estimate the risks associated with an identified operable unit before any remediation of a USDOE site, listed on the National Priorities List. These risk assessments use conservative assumptions, and commonly use simplistic transport models that produce approximate estimates of risk. The conservative assumptions used in the assessments are each chosen to provide an ample safety margin for protecting public health, and the interacting conservative choices tend to overestimate risks.

The conservative assumptions contained in these baseline assessments include the toxicity values and cancer risk factors, and worst-case conditions for land use, predicted environmental concentrations and exposure rates. The identified receptor for a baseline risk assessment is an individual receiving the "reasonable maximum exposure" [sic] (USEPA, 1989a), whether or not she or he exists.

Parameter values used in the models are usually point values, referred to as deterministic or default values. Use of deterministic values in risk assessments suggests that these are recognized as the true values because the calculations ignore variability and uncertainty of the parameters. Shevenell and Hoffman (1993) described the difficulties in ranking waste area groupings (or operating units) when deterministic risk assessments do not include uncertainty analyses.

USEPA (1989a) recommends use of conservative (e.g., 95 th percentile) values for some parameters and average values for others. It is difficult to sort out the 
uncertainty contributed by each parameter to an overall result of an EPA-type of assessment, because of the interactions among conservative and average values (Burmaster et al., 1990; Burmaster and Harris, 1993). Assignments of distributions as probability density functions (PDFs) in Monte Carlo analyses represent explicit attempts to account for the uncertainties associated with the parameters. Taylor (1993) recently reviewed methods for assigning distributions to parameters: 1) when appropriate data are sufficient for use of statistical approaches; 2) when a combination of objective and subjective methods is needed to construct appropriate distributions from data that are not directly relevant; and 3) when subjective methods must be used because relevant data are not available.

Commercial software packages are available for statistical analyses of the data bases and determinations of appropriate distributions of the data. For example, a simple log-probability plot can be used to determine whether data are normally or lognormally distributed. Lognormal distributions fit a straight line in these plots. In some cases, the choice of a lognormal distribution may be based on logical considerations. For example, there is ample evidence of induction of human bone and cranial sinus cancers after ingestion of ${ }^{226} \mathrm{Ra}$, but there is no evidence of causation of other types of malignancies in man. Approximately $65 \%$ of the cancer risk factor for USEPA's (1991b, c) proposed standard for ${ }^{226} \mathrm{Ra}$ in drinking water is based on risks to soft tissues. Possible risks of soft tissue cancers cannot be excluded, but their influence on the overall risk factor can be reduced by using a lognormal distribution to weight the factor in favor of cancers of bone and cranial sinuses (Morris et al., 1992).

The choice of a distribution type is based on professional judgment and has greater uncertainty when data are insufficient. This can happen when lower and upper extreme values of a parameter are known, but intermediary sampling is insufficient. One might choose to say that there is an equal chance for any value between the extremes (a uniform distribution), or select an intermediary value as a mode (a triangular distribution). Alternatively, commercial Monte Carlo software allows one to set up a custom distribution in which samples are selected in proportion to the frequency of the available measured values for a specific parameter.

Choice of distribution type and its contribution to the uncertainty of a risk assessment should be fully explained for all significant parameters.

Uncertainties can be over- or underestimated because the assumptions may not yield true extremes. The upper bound of uncertainty is especially important because most concentrations of environmental contaminants will be be low. Therefore, major concerns (regulatory or remedial) for exposures to the contaminants, and the risks generated by these exposures, will be at or above the upper bounds of uncertainty. Approaches to approximate the true bounds on uncertainty more accurately are described in succeeding sections and in Appendix 1. 


\subsubsection{Bounds on Interacting Parameters}

Combinations of statistically-correlated parameters in Monte Carlo simulations can either underestimate or overestimate the variances and extremes of the distribution (uncertainties) of the results, depending on the nature of the mathematical operations. A method of dependency bounds analysis has been described for determining the variability and bounds of distributions resulting from mathematical operations between correlated parameters (Ferson et al., 1993). This method might be a useful tool for sensitivity analysis when independence between parameters must be examined closely. Conquest (1993) also recently described simple methods for dealing with correlated parameters.

\subsubsection{Bayesian Analysis}

Bayesian analysis is a statistical method for updating uncertainties to account for newly acquired information (Brand and Small, 1993; Caudill, 1993). To estimate the distribution of a parameter the method relies on expert opinion or knowledge of existing data or information. Bayesian analyses are useful for combinations of objective and subjective information (Taylor, 1993). The subjectivity of Bayesian analyses has been criticized because the analyst is expected to "...use his or her own knowledge and beliefs to generate a probability model when objective factual knowledge is incomplete or inadequate" (Cox and Ricci, 1992). The opposing argument is "...that the analyst has no justification, and should not be expected or required to provide numbers in the absence of facts" (Cox and Ricci, 1992). Cox and Ricci (1992) also argue that using Bayesian methods to integrate new information may reintroduce ambiguity into specific risk models because of averaging over different possibilities.

\subsubsection{Fuzzy Logic}

Fuzzy logic is a form of approximate reasoning that is applied to continuous variables, known as fuzzy sets, where the range of possible values of each parameter is considered in calculations that usually yield more than one qualitative result (Caudill, 1993). Classification of a result is determined by weighted outputs from the interactions of fuzzy sets. This approach, used primarily for controlling devices in a variety of systems (the simplest example is turning a switch on or off after evaluation of variable inputs from several sensory devices), has also been suggested for use in risk assessment (Caudill, 1993).

\subsubsection{Second Order Uncertainties}

Second order uncertainties arise from unsuspected systematic errors. These errors produce uncertainties in the values of the bounds of distributions (uncertainties of parameters) in Monte Carlo risk assessments. Second order uncertainties tend to yield underestimated ranges of uncertainty. A proposed Monte Carlo analysis of risk uses an asymptotic exponential distribution in combination with a parameter, $\mu$, representing relative uncertainty of the standard deviation (Shlyakhter, 1993; Shlyakhter et al.,1993a, b). 


\subsubsection{Multiplicative Models}

Multiplicative models are illustrated in the pilot study by the risk analysis for the NTS (Daniels et al., 1993), where simple calculations were substituted firr Monte Carlo methods. These models are specifically constructed for lognormal distributions that interact by multiplication or division. The use of this approach in risk assessment was recently demonstrated by Slob (1993).

\subsubsection{Reliability Testing}

Reliability testing is a procedure for testing models. IAEA (1989) suggests that the best way to determine the extent of potential misprediction (reliability assessment), is a procedure called model validation that tests model predictions against "...independent (and appropriately) derived sets of data". Although proposed for validating environmental transfer models (IAEA, 1989), these tests can be applied to risk assessment models in general. Outputs of reliability tests do not determine specifically which elements of a model are the major sources of uncertainty, but magnitude of the error in the results can be used to determine the need for additional parameter uncertainty tests. Thus, newly acquired data on concentrations in the river were used to test assessment predictions of tritium releases from the SRS to the Savannah River. For the groundwater transport model this led to the detection of a relatively small error in source terms that did not have a significant impact on the final risk estimates (Hamilton, et al., 1993a).

\subsubsection{Two-Dimensional Distributions}

Computer software was recently developed to distinguish population heterogeneity from measurement error, by performing a Monte Carlo Analysis that yields a two-dimensional distribution for each parameter (Carrington and Bolger, 1993). The authors claim that this is a particularly useful approach for integrating dose-response analysis with exposure information, while avoiding stepwise "uncertainty management". A copy of this software was provided to the Biomedical and Environmental Assessment Group for testing.

\section{Prioritization of Uncertainties}

To prioritize uncertainties for risk assessments at USDOE facilities, a list of uncertainties (Table 1) was generated from the assessments that formed the pilot study and from discussions held as part of the Workshop on Uncertainty, at Brookhaven National Laboratory on August 4, 1993. These assessments were used to identify uncertainties because they provide a spectrum of types of problems, uncertainties and approaches to assessment. 


\subsection{Approach to Prioritization}

The first step in prioritization was to illustrate the list of uncertainties in Table 1 by using the pilot study and other risk assessments. In most cases it was difficult to make generic statements because of differences in pollutants and in risk assessment procedures required for different sites.

Table 1. Sources of Uncertainty Associated with Assessments of Health Risks at U.S. Department of Energy Facilities.

\section{Source Terms}

(1) Chemical or physical form of emission;

(2) Probability distribution of amounts emitted (routine, accidents); annual average emissions;

(3) Time distribution of emissions with respect to other important variables, such as transport conditions (e.g., weather) or locations and activities of exposed persons (e.g., day-night);

(4) Locations of emissions with respect to local transport mechanisms (e.g., streams, intervening topography):

(5) Effect of local conditions on amounts or form of emissions (e.g., weather, facility operations).

(6) Estimation models, assumptions, and approximations.

\section{Scenarios}

(1) Institutional control and future land use of a facility;

(2) Demography and changes in populations associated with a specific facility or region; and

(3) Future receptor locations in the region of a facility.

\section{Media and Transport}

(1) Soil characteristics - porosity and nature of soils (binding of pollutants), resuspension of soils, uptake from or deposition of soils on plants;

(2) Air - wind direction and velocity, chemical and physical interactions;

(3) Ground water - chemistry and chemistry-dependent hydrogeology; flow rates;

(4) Surface water - chemistry, hydrogeology, flow rates, sediments;

(5) Food chains - bioaccumulation in edible portions of animals and plants that are affected by the facility;

(6) Partitioning among media (air, water, land) and within components of media (e.g., food chains, deposition); chemical or physical transformations during transport; selection of important media for analysis;

(7) Values or distributions of physical constants (e.g., dispersion coefficients, chemical transformations);

(8) Seasonal distributions (e.g., weather, water flow);

(9) Outdoor-indoor relationships;

(10) Estimation models, assumptions, and approximations.

Sources of uncertainty range from site-specific to generic. In some assessments a generic distribution may be suitable for a specific parameter that does not have a major impact on the magnitude of the risk estimate. In others the same parameter is an important source of uncertainty. For example, a national database on a human activity may be suitable for use in some exposure assessments, while other assessments may require disaggregation of those data 
for specific subpopulations. Alternatively, data bases from a smaller population may be more broadly applied (Taylor, 1993). Similarly, data collected over a short interval (three-day USDA Survey) may be applied to a longer duration. A sufficient quantity of quality data will generally rovide the most comfortable level of uncertainty in a risk assessment. Such date. allowed the construction of empirical models to predict concentrations of $t$ itium in the Savannah river, in the assessment of releases from the SRS (Hamilton et al., 1993a).

Sometimes the data are insufficient or only qualitative descriptions are available for assessment. In these cases, subjective methods (expert judgment and experience) may be used to establish a semiquantitative estimate of a parameter distribution. For example, elicitation of expert opinions might be used to establish ranges of probabilities for different scenarios at a specific site. Expert judgments may also be used to extend parameters between generic and specific circumstances, an approach that is amenable to Bayesian analysis (Taylor, 1993).

Table 1. Continued

\section{Exposure Pathways}

(1) Temporal and spatial distributions of population density;

(2) Intake rates (breathing, eating, drinking, immersion); significant local demographic characteristics (e.g., age distribution, activity rates, time indoors and outdoors);

(3) Local differences in intake rates (e.g., consumption of local produce and fishes);

(4) Estimation models, assumptions, and approximations;

(5) Outdoor - time spent outdoors (may be age and job related), inhalation (including resuspended material), ingestion (soil), dermal (swimming, partial body contact. transfer rates);

(6) Indoor - time spent indoors (may be age and job related), workplace (inhalation, ingestion, dermal contact), home (inhalation in shower, bathroom or house), digestion (food, water, pica), dermal (bathing, washing, transfer rates).

Dose Response and Risk Factors

(1) Extrapolation of research results from animals at high doses and dose rates to humans;

(2) Extrapolation of research results from humans at high doses and dose rates to others at low doses and dose rates;

(3) Inclusion of only one response (e.g. death) for pollutants with many health and environmental impacts;

(4) Effects of confounding factors (e.g., smoking and cancer);

(5) Estimation of doses to affected tissues per unit exposure;

(6) Effects of natural variability in responses among humans;

(7) Estimation models, assumptions, and approximations.

\subsection{Important Sources of Uncertainty}

The word important refers to the size of uncertainty in a risk estimate, and the quantitative effect of a parameter or component of the assessment. One level of priority is to determine the important sources of uncertainty in risk assessments for USDOE facilities. This is done for a risk assessment by sensitivity and uncertainty analyses, as described above. The most important sources of uncertainty vary among risk assessments. 
In assessments of facilities in the USDOE complex the ultimate goal for prioritization is selection of the most important sources of uncertainty. Importance of parameter contributions to uncertainty will vary from assessment to assessment, although some generalizations can be made. This is exemplified by the assessments of two radionuclides in the Savannah River. The most important component of the exposure pathways for tritium was drinking water consumption, with only a minor role for ingestion of freshwater finfish. In contrast, finfish ingestion was the major pathway for exposure to ${ }^{137} \mathrm{Cs}$ in the river; 9 to 18 times the exposure from drinking water.

Important sources of uncertainty that were identified for risk assessments at USDOE facilities were reviewed to select uncertainties that can be addressed directly and cost-effectively by USDOE.

\subsection{Cost-effectiveness of Uncertainty Reduction or Replacing Uncertainty with Knowledge.}

Cost-effectiveness depends on value of increased information, relative to increased cost of the reduction process. Although uncertainty reduction may cost more than use of simple generic default values, such reduction provides more and better information. Uncertainties can be reduced cost-effectively for several reasons.

(1) Costs of remediation are far greater than risk assessment costs. "A risk assessment...could significantly expedite cleanup cycles and ultimately save the facility millions of dollars" (Callahan and McCaw, 1993).

(2) A need for best allocation of limited resources available for remediation choices. Reduction of uncertainties can provide better understanding of how much remediation is really needed. Better models can help to set priorities for remediation by reducing uncertainty and conservative assumptions, with savings on costs of remediating what are perceived to be problems when generic methods are used.

(3) Another value of additional and better information is the greater confidence provided to decision makers and the public. Greater confidence comes from explicit descriptions of uncertainties, combined with clear explanations of reduction of uncertainties, as opposed to a deterministic approach, in which contributions to overall uncertainty are difficult to sort out and explain.

The amount of additional information gained from a complex model depends, in part, on the amount of data available. Complexity of a transport model should match the data available at the site. Complex models require more data than simple models. If site-specific data are not available, and generic data must be used as input, much of the value of a more complex model will be lost. By running several cases in an assessment with a range of data inputs, a complex 
model may be used to help determine the value of obtaining additional data. This is a cost-effective approach because modelling is less expensive than field work.

\section{Major Uncertainties In Risk Assessment for USDOE Facilities}

\subsection{Source Terms and Site-Specific Information}

Source terms describe the contaminants that are released at a site, both qualitatively and quantitatively. Source terms drive the risk assessment, and adequacy of the data is a major issue. Source terms are site-specific; depending on the characteristics of each site, and the contaminants of concern. The highest scores in USDOE's Multimedia Environmental Pollutant Assessment System ranking, based on data collected in an environmental survey, usually coincided with the most uncertain source terms (Morris and Meinhold, 1988). Highly conservative assumptions were used to estimate those uncertain source terms.

In some cases, source terms are estimated directly from measured emissions. In other cases, they are indirectly estimated from environmental monitoring data, inventory estimates, and the application of environmental transport models. In these cases, the source terms are uncertain, but are, at least, based on some data and information.

Other situations at USDOE sites present a greater challenge and a higher degree of uncertainty in estimating a source term. Often, historical records are not available to estimate inventories of contaminants in landfills and other potential sources of environmental contamination. Source terms estimated for these situations are extremely uncertain, and only additional site characterization can effectively reduce the uncertainty.

A source term can be for a single release, repeated releases, or continued releases of contaminants, or any combination of these three. The combination can be expressed as a probability distribution of the range of a source term that varies with time.

For the assessment of ${ }^{3} \mathrm{H}$ at the SRS, variation with time was an important characteristic of the source terms (Hamilton et al., 1993a). Problems from the complex nature of the releases of $3 \mathrm{H}$ were simplified by developing an empirical model from annual data from 1954 to 1989 . The complex characteristics of the 300 square-mile site, including transport on the site by surface and ground waters, were also simplified by treating the site as a point source. The empirical model provided year-by-year probability distributions for the source terms. Sensitivity and uncertainty analyses demonstrated that unforeseen changes in some of the site characteristics (i.e., drought conditions, operations other than reactors) yielded uncertainty changes that did not affect the risk estimates markedly. 
Chemical and physical properties of the pollutant may have important effects on theirisk estimates. The chemical form is rarely known and is a significant source of unctrrtainty for many pollutants in landfills and other sources. In contrast, the physic J-chemical characteristics of cesium narrowed the uncertainty of the source term for ${ }^{137 \mathrm{C} s}$ by limiting releases to the Savannah River from the SRS (Hamilton et al., 1993a).

Source terms for the pilot study risk assessments at the FEMP were estimated by combining monitoring data with information on contaminant inventories and environmental transport modeling (Hamilton et al., 1993b). In the case of radon, risks were analyzed for atmospheric release from a silo, either continuously or from a catastrophic collapse. Release of uranium to ground water was treated as either continuous, or stopped at the source after a period of release.

For plutonium in soils at the NTS, measurements of soil concentrations at test locations were used to develop the source terms (Layton et al., 1993).

In contrast, at the NTS source terms were highly uncertain for underground test releases of radionuclides to ground water (Daniels et al., 1993). The quantities of different radionuclides available for transport, their spatial distribution on the site, and their movement to receptors in the groundwater (site characterization) were all highly uncertain because of a lack of data. This compelled the use of a screening assessment and conservative assumptions that highly-uncertain concentrations of each radionuclide are delivered to receptors. Contaminant sources are scattered over an area of 1350 square-miles.

In summary, source terms are generally important site-specific drivers of risk assessments. The contributions of source terms to uncertainty of risk assessments are inversely related to the quantity and quality of data available for source-term development. Therefore, it is important for USDOE and its contractors to obtain the information, needed to develop source terms for the problems at each site.

\subsection{Identification of Scenarios and Receptors}

\subsubsection{Scenarios}

Scenarios apply to use of sites and their environs. The suites of exposure pathways in the assessments and the risk results depend highly on scenarios. The definition of future land uses near USDOE sites requires major assumptions, and is extremely uncertain. For realistic risk assessments, It is assumed that land-uses in the future conform to current activities, or to current activities on nearby land, unless there is compelling evidence to the contrary.

The prospective use of a site is a decision of either USDOE or any government agency that holds title to the land. USDOE is working to involve local governments and other stakeholders in land-use decisions. Prospective use of sites may require institutional control for limited or undefined periods of time, depending on the types of pollutants, their concentrations and geographic distributions. The assumption of the maintenance or loss of institutional control 
at a USDOE facility can be critical to the results of a risk assessment when most of the identified contamination is onsite in soil or water. A loss of institutional control may require the use of an intruder scenario, and a scenario assuming the possibility of farming or a family living onsite, as in the assessment of plutonium-contaminated soil at the NTS (Layton et al., 1993). The nature of the pollutants at a site as large as the NTS makes groundwater and soil remediation prohibitively expensive. Therefore, institutional control, in perpetuity, would be a reasonable scenario (Daniels et al., 1993; Layton et al., 1993).

Other possible scenarios for USDOE sites include release of property for industrial, commercial or recreational use.

Offsite land use is expected reasonably to conform to current practices, and existing plans of local and regional governments. Such information is usually included in site descriptions, or may be obtained by contacting local authorities. These scenarios are also influenced by the relationships of offsite population locations to direction and mode of transport of pollutants.

These scenarios are critical parts of risk assessments for USDOE facilities, and contribute significant uncertainty, because they are qualitative assumptions about the future, which determine the suite of quantitative parameters to be used in the assessments.

\subsubsection{Identification of Receptors}

Receptors are either people who are currently exposed to the pollutant of interest, or people who have a reasonable potential for such exposure. Currently exposed people include onsite populations (usually workers), and local or regional populations, exposed because of environmental transport processes (e.g., wind, surface and groundwater movement). Potentially exposed people include people who reside in the path of a plume that is expected to reach them in the future, people that gain entry to the site as a result of a loss of institutional control, and additional people who may be exposed as a result of migration or population growth.

Offsite receptors can be close by, as in the case of receptors near the FEMP, consisting of a rural population distributed near the site fenceline (Hamilton et al., 1993b). Directional transport of pollutants was important in determining the potential receptors for uranium in ground water. Potential receptors were determined by the geographic extent of a modeled plume emanating from the FEMP.

Receptors can also be at a considerable distance, as in the case of the assessments at the SRS, where receptors were exposed to pollutants in Savannah River water approximately 100 miles from the site. The size of potential receptor populations is another consideration. In the case of the SRS, public utilities provided valuable information on the growth of the receptor populations (Hamilton et al., 1993a). 
The location of current receptors is reasonably certain in risk assessments for USDOE sites. As stated above, the uncertainty associated with the location of current receptors is largely determined by the uncertainty in environmental transport models. The location of future receptors, however, contributes significant uncertainty to risk assessments for USDOE facilities.

\subsection{Environmental Transport}

\subsubsection{Transport Models}

Environmental transport is movement of materials, by way of one or more media (atmosphere; surface water; soil; and groundwater), from a source to a receptor. Pollutants may contaminate water and food (vegetable and animal) and other materials (oral intake of nonnutritional items) by way of deposition and surface adhesion, or through uptake by plants and animals.

Contaminant concentrations in air, ground water, surface water and food are predicted by using environmental transport models appropriate to each site, each problem and the available data.

A large amount of uncertainty in risk assessments for USDOE sites is associated with the application of environmental transport models for air, ground water, surface water, overland runoff and soil resuspension. Uncertainty in the use of environmental transport models can be considered in several categories:

1. Uncertainties inherent in attempting to describe complex physical and chemical processes by using mathematical equations;

2. Uncertainties introduced when important simplifying assumptions of the models are contravened in model application;

3. Uncertainties associated with estimates of input parameter (data) values required by transport models.

Some of these contributions to uncertainty in transport modeling may be more important than others, depending on the specific situation. Additional uncertainties are added when it becomes necessary to combine several transport models in tracking a contaminant to a receptor. For example, the results of a groundwater transport model that requires simulation of leachate generation from a landfill are more uncertain than those from a model simulating movement of a contaminant discharge directly to an aquifer.

Air and surfacewater dispersion models are likely to be more certain than models of vadose zone and groundwater transport, and of overland runoff.

Important assumptions of transport models are often violated in real world applications. The uncertainty of a result is higher when such major assumptions are contravened. These assumptions may include an assumption of simple rather than complex terrain for a Gaussian plume air-transport model, and an assumption of homogeneous soil properties for a groundwater solute transport 
model. For example, the study by Hamilton et al. (1993b) on radon releases at the FEMP included uncertainty attributed to terrain features (e.g., bluffs running east to west, between the site and the community of Hamilton) that were not included in the generic model.

Similarly, soil-resuspension models, associated with atmospheric transport, may be modified for specific site characteristics, as was done for Pu in the soil at the NTS (Layton et al, 1993).

Where complex site-specific transport models were developed by the USDOE or site contractors, these models should be considered for use in the assessments. Empirical models may be used to relate a site's contaminant discharges to environmental concentrations at receptors, in place of models that describe transport processes, when a large amount of historical data is available. These site-specific models allow formulation of reasonable estimates of temporally related contaminant releases. Thus, contaminant concentrations in Savannah River water in recent years were used to predict distributions of annual concentrations in future water supplies to receptors, by using ratios of concentrations, near receptors, to respective concentrations, near the SRS (Hamilton et al., 1993a).

When sites and source terms are poorly characterized, more elementary models are developed and applied. Such models provide appropriate estimates of future environmental concentrations of the principal contaminants of concern, for use in a site-specific, risk-based screening analysis. For example, a simple travel-time-transport model was used for the groundwater movement of radioactive pollutants at the NTS (Daniels et al., 1993).

\subsubsection{Contaminant and medium properties.}

The physical and chemical properties of pollutants in emissions, relative to the properties of media, are important elements in transport, especially for partitioning of pollutants in various media. These properties may be elements of transport problems that range from site-specific to generic, and can contribute significantly to uncertainties in the final risk estimates. There is much basic research to be done on: distributions of physical 'constants' (e.g., partition coefficients, soil binding characteristics [ $K_{d}$ values] and dispersion coefficients); and the way chemicals are transformed or degraded in the various media (e.g., ultraviolet-induced transformations of organic compounds in the atmosphere, valence of ions such as $\mathrm{Cr}^{3+}$ or $\left.\mathrm{Cr}^{6+}\right)$. Many of these values are site and contaminant specific.

The importance of these parameters can be illustrated by validation (i.e., reliability testing) of the transport model used in the assessment at the FEMP, of health risks from uranium in ground water (Hamilton et al., 1993b). Generic $K_{d}$ values would have yielded underestimates of future extents of the plume, and underestimates of the number of potentially impacted wells in the path of the plume. IT Corporation calculated a range of $K_{d} S$ and retardation coefficients for uranium in offsite ground water based on calibrating a three-dimensional solute 
transport model with monitoring data. Values calculated by IT (K $\left.K_{d} s 1.0-1.34\right)$ were low compared to generic values ( $K_{d} s$ about 40 ), but were consistent with the expected moderate $\mathrm{pH}$ and oxidative nature of the FEMP surficial aquifer.

Tritium (in the form of HTO) was assumed to be freely miscible in Savannah River, in the assessment at the SRS. Cesium tended to bind to sediments of surface waters, with only limited release for transport in solution or resuspension (Hamilton et al., 1993a). Less certain was the transported form of uranium as it left the FEMP in groundwater (Hamilton et al., 1993b).

Groundwater transport was highly uncertain because site- and contaminantspecific $K_{d} S$ were unknown for many of the radionuclides at the NTS, and the conservative model used did not incorporate adsorption (Daniels et al., 1993).

Interactions of contaminants with biological elements in the environment may affect transport in ways that either increase or decrease exposure of receptors. Thus, uptake and transpiration of tritiated water by vegetation had a considerable influence on tritium concentrations in groundwater at the SRS and Lawrence Livermore National Laboratory (Hamilton et al., 1993a; Mallon et al., 1991).

Transport and bioconcentration in the food chain also affect human exposures and health risks. For example, as a result of bioconcentration, finfish were the major route of exposure to ${ }^{137} \mathrm{Cs}$ in Savannah River water (Hamilton et al., 1993a). Similarly, ingestion was a major route of human exposure to radionuclides that entered the food chain as a result of fallout from the Chernobyl accident (Cooper et al., 1992; Shiraishi et al., 1992). Finfish were major routes of exposure in an assessment of radium in produced waters from oil and gas wells in the Gulf of Mexico (Meinhold et al., 1993). In the pilot study, meat, dairy products and homegrown vegetables were exposure pathways from groundwater contamination by uranium at the FEMP (Hamilton et al., 1993b), and from soil contamination by plutonium at the NTS (Layton et al., 1993).

Concentrations of chemical and radioactive contaminants in human foods are an active area of study, with a large database generated by the USDA's Total Diet Study (Market Basket Survey). However, these data may have to be reorganized and reanalyzed so that they are suitable for risk assessments at USDOE facilities. One important piece of dietary information that has to be extracted is a range of background concentrations for contaminants of concern, that could be applied either across broad regions or nationally.

\subsection{Exposure Pathways and Parameters}

Exposure is the quantity of pollutant that contacts a receptor at the point(s) of intake. Interactions of two basic components determine the degree of exposure:

1) the concentration in each medium derived from transport processes;

2) the rate of intake of each medium derived from biological and behavioral attributes of receptors. 
The first component is ultimately determined by scenarios, source terms, and transport processes, as discussed in previous sections. The attributes that form the second component are also known as pathway exposure factors (PEFs McKone, 1990; McKone and Daniels, 1991). Although, generic distributions were? developed for PEFs, specific demographic characteristics may have significant effects on these distributions (Table 1). Such characteristics include specific ages and activity rates of susceptible fractions of receptor populations, and time spent indoors and outdoors by these receptors. Factors, such as ethnic food preferences, may significantly affect exposure patterns. Uncertainty associated with generic distributions may or may not be reduced by disaggregation for specific receptor populations.

Direct exposure to a contaminant by inhalation or ingestion in water is more certain than exposure by ingestion of contaminated crops or meat. Estimating concentrations in foodstuffs is complicated by the additional steps from transport to exposure imposed by the food chain. Exposure models for crops and meat use uncertain transfer factors to estimate the concentrations of contaminants in plants and livestock. Commonly used factors are often based on correlations between the transfer factors and the octanol-water partition coefficients $\left(K_{\text {ow }}\right)$ of each contaminant. The chemical forms of the contaminants (even radionuclides) for given contaminant sources are not clear. In addition to the inherent physicochemical basis for the uncertainties, the correlations ignore the complexity arising from bioconcentration at each step of the food chain. This lack of knowledge increases the uncertainties associated with the transfer factors. For radionuclides, NCRP (1984) published a list of measured transfer factors that are generally more certain than the factors based on octanol-water partition coefficients.

Exposure pathways may be highly specific to a problem or a contaminant. For example, drinking water intake was the major pathway of exposure (approximately $85 \%$ ) to tritium in the Savannah River (Hamilton et al., 1993a). Drinking water intake was secondary to freshwater finfish intake as an exposure pathway for ${ }^{137} \mathrm{Cs}$ in the Savannah River, because of bioconcentration of cesium in fish cells, and removal of cesium from drinking water by water purification.

Food intake, especially of homegrown food, may be an important pathway for exposure because USDOE facilities are often associated with rural areas. This pathway was analyzed for the assessments of groundwater uranium at the FEMP (Hamilton et al., 1993b) and soil plutonium at the NTS (Layton et al., 1993). There is clearly a need to address concentrations of contaminants in the food chain and feeding characteristics of human populations associated with USDOE facilities. Accordingly, there should also be information on background levels of contaminants in foodstuffs. At present, data for the United States are available from the USFDA's Total Diet Study (= Market Basket Survey; USEPA, 1992a).

Sensitivity analyses are necessary early in the risk assessment process to determine which exposure pathways and uncertainties are most important to the final risk estimate (Appendix 1). Efficiency of the risk analysis is increased by 
elimination of exposures and treatments of uncertainties that do not have a significant impact on the final risk estimates. Dermal exposures to ${ }^{3 \mathrm{H}}$ and ${ }^{137} \mathrm{Cs}$ from bathing and swimming in water from the Savannah River, orders of magnitude less than from other pathways, did not significantly affect the risk analyses at the SRS (Hamilton et al., 1993a). Relative importance, however, is no guarantee that uncertainty of a specific exposure pathway will have a major influence on the final risk results. Uncertainty about the intake rate: of drinking water from the Savannah River did not significantly affect the final risk estimates, although drinking water was the predominant pathway of exposure to ${ }^{3} \mathrm{H}$.

Duration of exposure is another source of uncertainty. A simple screening analysis usually assumes exposure over a 70-year lifetime. This exposure period and its influence on lifetime risk will be discussed in section 5.5.3. Actual duration of exposure may depend upon such factors as: persistence of a pollutant in the medium by which people are exposed; duration of residence or duration of employment of people at an exposure location; and age associated activities (indoor and outdoor: Hamilton et al., 1993b; Layton et al., 1993). A risk assessment of the uranium plume at the FEMP (Hamilton et al., 1993b) used a time-based movement of uranium concentrations (at ten-year intervals) in a groundwater plume. USEPA (1989a) recommends 30 years, the upper $90^{\text {th }}$ percentile, as a default value for residence duration. An assessment of radon exposure (ibid.) assumed distributions of rural residence (averaging 7.8 years) and urban residence (averaging 4.19 years), based on analysis (Israeli and Nelson, 1992) of data collected by the US Department of Commerce (1988, 1989). Meinhold et al. (1993) used a distribution of 1 to 30 years as an occupational span for workers exposed to radium in produced waters on offshore oilfield platforms in the Gulf of Mexico, as opposed to USEPA's default value of 50 years employment for all workers. Layton et al. (1993) did similar analyses of residential and occupational durations.

Risk factors and risk results are commonly expressed as per quantity of exposure, although exposure is usually not the same as dose (see next section). Thus, USEPA's HEAST document (USEPA, 1991b) expresses toxicity and slope factors amount of contaminant per unit of exposure medium (e.g., $\mu \mathrm{g} / \mathrm{g}$ or $\mathrm{g} / \mathrm{L}$ ).

\subsection{Dose-response Models and Risk Factors}

\subsubsection{Contaminant Specific Information}

Many contaminants, including radionuclides, inorganic and organic chemicals have been detected in air, soil, surface and ground water at USDOE sites. Important contaminants that may be risks to human health were identified for individual ranking units for all USDOE sites as part of an environmental survey. The Multimedia Environmental Pollution Assessment System's (MEPAS) analyses of the environmental survey data were used to make relative rankings of human health risks (Morris and Meinhold, 1988). 
A list of the contaminants scoring the highest for each ranking unit (and presumably presenting the highest potential human health risk) is available for each site. Table 2 summarizes the number of sites at which a given contaminant scored the highest for any ranking unit at the site. This list represents a reasonable basis for identifying the contaminants likely to be of most concern for USDOE facilities.

Table 2. Contaminants scoring at more than one DOE facility in MEPAS modeling of the USDOE Environmental Survey: by descending number of sites (USDOE Environmental Survey Database).

\begin{tabular}{|c|c||l|c|}
\hline Radionuclides & $\begin{array}{c}\text { Number } \\
\text { of Sites }\end{array}$ & Chemicals & $\begin{array}{c}\text { Number } \\
\text { of Sites }\end{array}$ \\
\hline $238 \mathrm{U}$ & 10 & PCBs & 12 \\
$3 \mathrm{H}$ & 9 & 1,1,1-Trichloroethane & 9 \\
$235 \mathrm{U}$ & 9 & 1,2-Dichlorethane & 9 \\
$238 \mathrm{Pu}$ & 8 & Gasoline & 9 \\
$239 \mathrm{Pu}$ & 7 & Tetrachloroethylene & 8 \\
$137 \mathrm{Cs}$ & 6 & Trichloroethylene & 6 \\
$235 \mathrm{U}$ & 6 & Carbon Tetrachloride & 5 \\
$240 \mathrm{Pu}$ & 5 & Chloroform & 5 \\
$99 \mathrm{TC}$ & 5 & 1,2-Dichloroethylene & 4 \\
$232 \mathrm{Th}$ & 5 & Chromium VI & 4 \\
$241 \mathrm{Am}$ & 4 & 1,1-Dichloroethylene & 3 \\
$60 \mathrm{Co}$ & 4 & Benzene & 3 \\
129 & 3 & Diesel Fuel & 3 \\
$228 \mathrm{Th}$ & 3 & Methylene Chloride & 3 \\
$131 !$ & 2 & Acetone & 2 \\
$63 \mathrm{Ni}$ & 2 & Arsenic & 2 \\
$226 \mathrm{Ra}$ & 2 & Asbestos & 2 \\
$222 \mathrm{Rn}$ & 2 & Dimethyl Formamide & 2 \\
& & Hydrazine & 2 \\
& & Lead & 2 \\
& & Mercury & 2 \\
\hline
\end{tabular}

Dose-responses are contaminant specific, to the point where chemical behavior is similar in physiological systems. Dose refers to the actual amount of deleterious material delivered to a susceptible target (i.e., cells, organs or organism). Although external exposure to radiation, such as UV irradiation of the skin, may be equivalent to a dose, in most cases, contaminant intakes undergo complex pharmacokinetic processes that yield the doses to target organs and tissues. Safety and risk factors should account for the chemical forms (e.g., valence) of pollutants, because of chemically-mediated effects of uptake, pharmacokinetics, interactions with target molecules, and retention, on dose. Although there is a trend toward using pharmacokintetic investigations to understand and model dose-response relationships, these relationships are still a major area of uncertainty in risk assessment. 
In the absence of appropriate pharmacokinetic information, it is easier to express risk in terms of exposure than in terms of dose. This does not reduce the uncertainty associated with risk estimate.j, and the lack of understanding of actual dose needed to obtain a specific effect may add to the uncertainty. Although most of the following discussion refers to 'dose', in many instances it really means exposure.

Two aspects of dose to be considered are total dose and dose rate. There are numerous uncertainties associated with total dose and dose rate, especially when the dose-response relationship is modeled as linear, as in carcinogenesis.

In these cases, it is the low doses and dose rates that are of concern because we have the least knowledge at these low levels. The assumed relationships of the responses to doses are often based on various types of extrapolations (see section 5.5.3 below).

\subsubsection{USEPA Toxicity Values for Chemicals and Radionuclides}

According to USEPA 1989a (page 7-3), toxicity values are numerical expressions of dose-response relationships that are used in the risk characterization stage of an assessment for both cancer and noncancer risks. The reader is referred to chapter 7 in USEPA 1989a for detailed descriptions and derivations of different types of toxicity values, which fall into two basic categories: reference doses for most forms of noncancer toxicity; and slope factors for cancer and some forms of noncancer toxicity. USEPA 1989 a also provides the procedure for obtaining toxicity values from sources such as USEPA's Integrated Risk Information System (IRIS).

For simplicity, this report will refer to all forms of noncancerous detrimental effects as toxicity. The USEPA (1989a) uses a chronic reference dose (RfD) for toxicity from postnatal chronic (seven years to lifetime) exposures to a contaminant. A variety of acronyms are used for other types of exposures. The RfD is "an active estimate (with uncertainty spanning perhaps an order of magnitude or greater) of a daily exposure level for the human population, including sensitive subpopulations, that is likely to be without an appreciable risk of deleterious effects during a lifetime. Chronic RfDs are specifically developed to be protective ... (Italics added to the quote)."

Each RfD includes uncertainty factors (UFs) and a modifying factor (MF). Depending on the derivation of the RfD, uncertainty factors can inflate the RfD by up to 10,000 times. The MF is "a qualitative professional assessment of uncertainties...not addressed by the preceding uncertainty factors ${ }^{*}$, with a default value of 1 , on a scale of $>0$ to 10. Information in IRIS includes an expression of USEPA evaluators' confidence in the RfD; described as either high, medium or low. Therefore, an estimated exposure that exceeds an RfD for a particular contaminant may or may not exceed a threshold for toxicity. Toxicity values of many of the chemicals commonly found at USDOE facilities are highly uncertain, as shown in Table 3 for the toxic chemicals listed in Table 2. 
Table 3. Oral RfDs from USEPA's IRIS for Toxic Chemicals at USDOE Sites.

\begin{tabular}{|l|c|c|c|}
\hline \multicolumn{1}{|c|}{ Chemical } & $\begin{array}{c}\text { Overall } \\
\text { Uncertainty }\end{array}$ & $\begin{array}{c}\text { Modifying } \\
\text { Factor }^{1}\end{array}$ & $\begin{array}{c}\text { Confidence } \\
\text { in } \\
\text { Uncertainty }\end{array}$ \\
\hline \hline PCBs (Aroclor 1016) & 100 & 1 & $M$ \\
Trichloroethylene & 1,000 & 1 & $M$ \\
Chloroform & 1,000 & 1 & $M$ \\
1,2-Dichloroethylene & 1,000 & 1 & $M$ \\
Chromium VI & 1,000 & 1 & $L$ \\
1,1-Dichloroethylene & 500 & 1 & $\mathrm{~L}$ \\
Benzene & 1,000 & 1 & $\mathrm{~L}$ \\
Arsenic & 1,000 & 1 & $\mathrm{~L}$ \\
Asbestos & 3 & 1 & $\mathrm{M}$ \\
Silver & 3 & 1 & $\mathrm{~L}$ \\
Uranium & 1,000 & 1 & $\mathrm{M}$ \\
Nickel (soluble salts) & 300 & 1 & $\mathrm{M}$ \\
\hline 1On a scale of 1 to 10. & \multicolumn{2}{|c|}{$\mathrm{H}=$ High; M = Medium; L = Low. }
\end{tabular}

Table 4. Weight-of-Evidence from USEPA's IRIS for Human Carcinogenicity of Chronic Low Doses of Chemical Contaminants at USDOE Sites

\begin{tabular}{|c|c|c|}
\hline Chemical & $\begin{array}{l}\text { Weight-of- } \\
\text { Evidence }^{1}\end{array}$ & Exposure \\
\hline $\begin{array}{l}\text { PCBs } \\
\text { 1,2-Dichlorethane } \\
\text { Carbon Tetrachloride } \\
\text { Chloroform } \\
\text { 1,2-Dichloroethylene } \\
\text { Chromium VI } \\
\text { 1,1-Dichloroethylene } \\
\text { Benzene } \\
\text { Methylene Chloride (Dichloromethane) } \\
\text { Acetone } \\
\text { Arsenic, inorganic } \\
\text { Asbestos } \\
\text { Hydrazine } \\
\text { Lead } \\
\text { Mercury } \\
\text { Nickel } \\
\text { Silver }\end{array}$ & $\begin{array}{c}\text { B2 } \\
\text { B2 } \\
\text { B2 } \\
\text { B2 } \\
\text { D } \\
\text { A } \\
\text { C } \\
\text { A } \\
\text { B2 } \\
\text { D } \\
\text { A } \\
\text { A } \\
\text { B2 } \\
\text { B22 } \\
\text { D } \\
\text { A } \\
\text { D }\end{array}$ & $\begin{array}{l}\text { Oral } \\
\text { Oral, Inhalation } \\
\text { Oral, Inhalation } \\
\text { Oral, Inhalation } \\
\text { Inhalation } \\
\text { Oral, Inhalation } \\
\text { Oral, Inhalation } \\
\text { Inhalation } \\
\text { Inhalation } \\
\text { Oral, Inhalation } \\
\text { Inhalation }\end{array}$ \\
\hline
\end{tabular}

1Specific descriptions of uncertainties associated with slope factors for each chemical are presented in IRIS (A, Human carcinogen; B1, Probable human carcinogen based on limited human data; B2, Probable human carcinogen based on sufficient evidence in animals only; C, Possible human carcinogen; D, Not classifiable as to human carcinogenicity; E, Evidence of noncarcinogenicity in human beings).

2 No data in IRIS. 
A slope factor is "a plausible upper-bound estimate of the probability of a response per unit intake of a chemical over a lifetime. The slope factor is used in risk assessments to estimate an upper-bound (italics added) lifetime probability of an individual developing cancer as a result of a lifetime exposure to a level of a particular carcinogen." The upper bound is usually the upper $95^{\text {th }}$ percent limit of the slope of a calculated dose-response curve. "In some cases slope factors based on humian dose-response data are based on the "best" estimate instead of the upper $95^{\text {th }}$ percent confidence limits."

Each USEPA slope factor is accompanied by a weight-of evidence classification, a "...system for characterizing the extent to which the available data indicate that an agent is a human carcinogen." This classification, described in Table 4, is a qualitative source of high uncertainty for many of the chemicals commonly found at USDOE sites. For example, most of the degreasers and solvents that are important contaminants at USDOE sites, particularly in ground water, are classified as probable or possible human carcinogens. Weight-of evidence classifications were also developed for some forms of toxicity, such as developmental effects.

Risk of radiation-induced cancer is generally derived from data in humans, coupled with extensive animal experiments, and generally is better understood than the carcinogenic risk of exposure to chemicals. Major uncertainties still exist, however, and are associated with the need to rely on extrapolations from data derived from high exposures to the levels experienced in most environmental exposures. The assumption of a linear no-threshold model introduces uncertainties into the dose-response relationships, but is still the most widely accepted method for estimating dose. There are, however, cases where a threshold for effects is likely to be the case (e.g., radium exposures) and major uncertainties and conservatisms are introduced into risk assessments when no threshold is assumed (Morris et al., 1992).

\subsubsection{Extrapolations}

Extrapolations are major contributors to the UFs in RfDs and uncertainty in slope factors.

Slope factors, estimated by linear extrapolations from responses at high (or acute) doses to low doses of radiation or chemicals, may either overestimate or underestimate risks. For example, the epidemiological data for bone cancers in humans exposed to ${ }^{226} \mathrm{Ra}$ and ${ }^{228} \mathrm{Ra}$ was described as a practical threshold for carcinogenesis (USEPA, 1991b). In contrast, doses above a particular level may have more than one effect, effectively depressing the appearance of cancer because of competing risks. Extrapolation below that level would result in underestimation of carcinogenesis (Goldsmith and Kordysh, 1993).

There are problems in extrapolation from other species to man. These problems usually involve the use of high doses and dose rates in experimental animals. According to USEPA 1989b, "The choice of a low-dose extrapolation model greatly influences estimates of the Carcinogenic Potency Factor and calculated risks. This uncertainty contributed by the model is substantial when predicting 
risks below 10-2." Furthermore, extrapolations of slope (potency) factors from animal bioassays to man have uncertainties that range up to nine orders of magnitude, although relatively little uncertainty may be associated with the bijassays per se (USEPA, 1989b).

For dose rates, adjustments must be made in going from acute exposures to chronic or intermittent low-level exposures (i.e., DREFs = dose-rate effectiveness factors), and the effects of different qualities (LET = linear energy transfer) of radiation (RBE $=$ relative biological effectiveness). Furthermore, extrapolations for susceptibility to an agent are complicated by uncertainty from intraspecific and interspecific variability. Variability may be qualitative (e.g., organ-specific) as well as quantitative.

The same dose and dose-rate problems exist when the extrapolations are based upon exposures of humans, notably in the case of people exposed to radiation at Hiroshima and Nagasaki (Fry, 1993). Extrapolations from the Japanese to populations in the U.S. are also uncertain because of differences in background rates of various types of cancers in Japan and the U.S. (ibid.).

Duration and period of exposure are additional sources of uncertainty in extrapolating from animals to man, and from one human population to another (Fry, 1993). Assessments generally use a lifetime of exposure to obtain a lifetime risk. As discussed in the section on exposure, duration of exposure is usually not for an entire lifetime. Humans and laboratory animals are usually exposed for a period at some part of their life. This brings up questions of variation in susceptibility during a lifetime. In the case of carcinogenesis, latency of response calls into question the risk of cancer from exposures during the last years of a lifetime, especially when low doses and dose rates are involved in risk assessment. For the assessments at the SRS, lifetime risks were based upon annual exposures (Hamilton et al., 1993a), allowing for year-to-year variation of exposure distributions. Exposures to uranium from groundwater at the FEMP were based upon average concentrations over ten-year intervals (Hamilton et al., 1993b). The distribution of fishing duration by sports fishermen near offshore platforms was a major consideration in analyses of exposure of the public to radium from produced waters from offshore oil fields (Meinhold et al., 1993).

To get around the extrapolation problems described above, Fry (1993) suggested that life-shortening, as a fraction of total life span, may have a linear relationship to dose that can be extrapolated from animals to man with relatively little uncertainty. Fry also suggested that life-shortening could be used to estimate radiation DREFs and RBEs because "life-shortening is an integrated effect of excesses of various types of cancers when the doses and dose rates are low".

The agents described in Table 2 are not necessarily the most significant pollutants at each site, but the strict regulatory mandates of federal, state and local agencies make it worthwhile for USDOE to reanalyze dose and risk factors. Although USEPA may have the lead in setting regulatory levels for each contaminant, safety factors, as high as a thousand times, increase already existing uncertainty. Many of USEPA's values for radionuclides are based upon 
work done by USDOE laboratories. This is an iterative process, in which the values change with new analyses and information. For example, according to the news media, USDOE is soliciting information about people exposed to radiation, mostly low-level, during the past 55 years (Holden, 1993; Stone, 1993). New information might be used cost-effectively to modify risk factors because the information has to be analyzed for incidence of health effects anyway.

\section{Prioritization of Uncertainties}

\subsection{Most Important Sources of Uncertainty Across the DOE Complex}

Table 5. Major Uncertainties in Risk Assessments for USDOE Facilities.

Dose-Response and Risk Factors
Partitioning of Pollutants Among Media and Within Components of
Media
Scenarios - Institutional Control and Future Land Use
Exposure Pathways and Pathway Exposure Factors
Source Terms

We used the discussions presented in previous sections, and the experience gained in the Pilot Study, to select the five most important sources of uncertainty in risk assessments at USDOE facilities (Table 5). They are not ranked because their relative contributions to the uncertainty of any assessment will vary with the amount and quality of information and data that is available.

Dose-response and risk factors are major generic sources of uncertainty, in part because of the protective uncertainty features built into these factors by regulatory agencies. As discussed above, even the classification of human carcinogenicity is highly uncertain for many of the chemicals at USDOE facilities.

Partitioning of pollutants during transport to receptors is to some degree site and region specific, depending upon physico-chemical conditions that are related to specific problems and modeling of transport. Where there are sufficient high quality data, this parameter may be a less important contributor to the overall uncertainty of a risk assessment. In the assessment of tritium in the Savannah River (Hamilton et al., 1993a) it was safe to assume that there was total mixing of tritiated water with river water. However, uncertainty of the flow rates of the river was the largest source of overall uncertainty (as manifested in the distributions of concentrations), slightly exceeding the uncertainty of the risk factor for cancer mortality. In the assessment of radionuclides at the NTS, lack of knowledge 
about concentrations of pollutants was among the largest sources of uncertainty (Daniels et al., 1993).

Scenarios can be the major source of uncertainty, depending upon specific problems at specific sites. Institutional control can be a major impact on determining who is at risk and the overall uncertainty of the risk. In the risk assessments at the Savannah River Site, and Fernald (Hamilton et al., 1993a,b), uncertainties were limited because established receptor populations were identified. In contrast, the assessments at the NTS combined loss or no loss of institutional control with hypothetical offsite and hypothetical onsite receptors (Daniels et al., 1993; Layton et al., 1993).

Exposure pathways and pathway exposure factors specifically refer to items that concern intakes of pollutants, and behavioral factors that contribute to intake. The uncertainties associated with this topic come from regional- or site-specific characteristics of the receptor populations in question. Although there are national data bases for this information as described above, they may require analyses that are pertinent to risk assessments for regions associated with specific USDOE sites. For example, food intake patterns may be of special concern for specific ethnic groups (e.g., Native Americans) that are receptors associated with specific facilities. In the risk assessment at the Savannah River Site, freshwater finfish ingestion was the major exposure pathway for ${ }^{137} \mathrm{Cs}$ intake, but not an important pathway for ${ }^{3} \mathrm{H}$ intake (Hamilton et al., 1993a). In an assessment of plutonium at the NTS homegrown foods were important pathways for exposure (Layton et al., 1993). Furthermore, indoor and outdoor activities were important to the assessment of inhalation exposure to plutonium, at the NTS (Layton et al., 1993), and exposure to radon released at the FEMP (Hamilton et al., 1993b).

Source terms are intrinsic site-specific parameters. Their contribution to overall uncertainty of risk assessments is an outstanding example of the need for adequate quantities of high quality data. There was an extensive history. of monitoring and data collection at the SRS, long before the existence of the USEPA (Hamilton et al., 1993a). The radon source terms at the FEMP K-65 silos were reconstructed (Hamilton et al., 1993b) from data that were obtained from extensive monitoring activity, which was not specifically designed for risk assessment purposes. At the other end of the spectrum, source terms for radionuclide contributions to groundwater, after underground tests at the NTS, were highly uncertain; causing the use in the analyses of the most conservative values for radionuclide concentrations (Daniels et al., 1993). 


\subsection{Recommended Research on Uncertainties that DOE Can Reduce Cost- effectively.}

Table 6. Major Uncertainties in Risk Assessments For USDOE Facilities,
Appropriate for USDOE Research Dose and Risk Factors for Chemical Agents

Exposure Pathways Associated with Ingestion of Foodstuffs

Of the five parameters identified as major sources of uncertainty in risk assessments at USDOE facilities (Table 5), two were identified for special attention for USDOE support (Table 6). The other three (pollutant partitioning in transport media; scenarios; and source terms) were not included for several reasons. As site specific problems, scenarios and source terms must be considered as DOE responsibilities for the procedures that are intrinsic parts of each risk analysis. The distributions of pollutants between and within transport media are problems that may be handled by the transport modelling in risk assessments for specific sites, and the acquisition of data to validate the models.

Reduction of uncertainties associated with dose and risk factors for chemical agents is cost-effective because the chemicals are commonly found at more than one USDOE site (Table 2). Dose and risk factors established by regulatory agencies such as the USEPA have compounded uncertainties built into their values for protective purposes. These uncertainties compound those that are inherent in the data from which these factors are derived, making the factors unsuitable for estimating the realistic risks that will contribute USDOE's risk management decisions. Therefore, it is suggested that attempts to reduce these uncertainties initially reexamine the factors established by regulatory agencies, and take into account any new scientific information that is available.

The recommendation specifically applies to chemical agents, as opposed to radionuclides, for two reasons. USDOE traditionally was and is involved in analyzing radionuclides for dose and risk information. Furthermore, in comparison to chemical agents, the values for radionuclides are better understood. There will be relatively few changes that will produce significant reductions in the uncertainties, especially for chronic low-dose exposures.

Although other organizations have collected information and data that are useful for establishing parameter values for exposure pathways, this has not been done in a way that is consistent with regions associated with USDOE facilities. This is particularly true for foodstuffs, where data collected by the USFDA on a national and broad regional basis makes it cost-effective for USDOE to support analyses that will reduce uncertainties associated with USDOE facilities around the nation.

For example, USFDA's Total Diet Study (= Market Basket Study) contains updated yearly information on human dietary intakes of foods and selected 
agents (both chemical and radionuclide) in foods for the U.S. population in four broad geographic areas (USEPA, 1992b). Before analyses, the foods are prepared (cooked) for human consumption, yielding more realistic values of exposure than those obtained from raw foods. Age and sex population groups are accounted for in the data. It may be feasible to narrow the information to smaller geographic areas associated with USDOE facilities, because the data base also contains identifiers for more local sources of data collection (i.e., city, municipality or township, standard metropolitan statistical area, and state). Information on background values of contaminants in foods might also be extracted from this data base. Computerized data are available from 1982 to the present (USEPA, 1992b).

Besides the analyses recommended for specific sources of uncertainty, USDOE should also support investigations by mathematicians and statisticians on the applications of methods for analyzing uncertainties in risk assessments; especially interacting uncertainty bounds, Bayesian analyses, fuzzy logic, and second-order uncertainties analyses.

\section{Summary and Conclusions on Reduction of Uncertainty}

This report explored the sources of uncertainty in realistic risk assessments at USDOE facilities, based upon examples primarily drawn from a successfully completed pilot study. It also used information from a recent workshop on uncertainty, and elsewhere: to explore the terminology associated with uncertainty; and to suggest exploration of analytical methods for reducing uncertainties in risk assessments.

Major sources of uncertainty were identified, but could not be generically quantified because their contributions to the overall uncertainty of a risk assessment are specific for each problem. However, five major sources of uncertainty, whose reduction may be DOE's responsibility or interest, were identified from the group. Of these five, two (dose and risk factors for chemicals; and exposure pathways for contaminants in foodstuffs) were recommended as topics for cost-effective investigations by USDOE for purposes of reducing uncertainties in realistic risk assessments. 


\section{References}

Brand, K.P., and M.J. Small, 1993, Bayesian updating applications to environmental health risk assessment. C/F-TPM-1-16, Final Program and Abstracts, Annual Meeting, Society for Risk Analysis, McLean, VA.

Burmaster, D.E., and R.H. Harris, 1993, Perspective: the Magnitude of compounding conservatisms in superfund risk assessments. Risk Anal. 13: 131-134.

Burmaster, D.E., Thompson, K.M., Menzie, C.A., Crouch, E.A.C., and McKone, T.E., 1990, Monte Carlo Techniques for Quantitative Uncertainty Analysis in Public Health Risk Assessments. Superfund '90, Hazardous Materials Control Research Institute, Silver Spring, MD, pp 215-221.

Callahan, B., and McCaw, P.A., 1993, Risk assessment alleviates environmental liabilities. Hydrocarbon Processing 72: 61.

Carrington, C.D., and Bolger, P.M., 1993, Two-dimensional Monte-Carlo simulation: uses and technique. D-POSTER-05, Final Program and Abstracts, Annual Meeting, Society for Risk Analysis, McLean, VA.

Caudill, M., 1993, The possibilities of probabilities. An Expert 8: 28-31.

Conquest, L.D., 1993. Statistical approaches to environmental monitoring: Did we teach the wrong things? Environ. Monitor. Assess. 26: 107-124.

Cooper, E.L., Zeiller, E., Ghods-Esphahani, A., Makarewicz, M., Schelenz, R., Frindik, O., Heilgeist, M., and Kalus, W., 1992, Radioactivity in food and total diet samples collected in selected settlements in the USSR. J. Environ. Radioactivity 17: 147-157.

Cox, L.A., Jr., and Ricci, P.F., 1992, Dealing with uncertainty from health risk assessment to environmental decision making. J. Energy Engineering 118: 77-94.

Daniels, J.I., Andricevic, R., Anspaugh, L.R., and Jacobson, R.L., 1993, "RiskBased Screening Analysis of Ground Water Contaminated by Radionuclides Introduced at the Nevada Test Site (NTS)," in Pilot Study Risk Assessment for Selected Problems at the Nevada Test Site (NTS), J.I. Daniels, Ed., Lawrence Livermore National Laboratory, Livermore, CA, UCRL-LR-113891, pp. 69-97.

Ferson, S., Oden, N., and Long, T.F., 1993. Dependency bounds on probabilistic risk assessments. D-WAM-07, Final Program and Abstracts, Annual Meeting, Society for Risk Analysis, McLean, VA.

Fry, R.J.M., 1993, The role of animal experiments in estimates of radiation risk. Adv. Radiat. Biol. 16: 181-197.

Goldsmith, J.R., and Kordysh, E., 1993, Why dose-response relationships are often non-linear and some cosequences. J. Expos. Anal. Environ. Epidemiol. 3: $259-276$.

Habicht, F.H., II, 1992, Guidance on Risk Characterization for Risk Managers and Risk Assesors. Memorandum from the Office of the Administrator, United States Environmental Protection Agency, Washington, DC.

Hamilton, L.D., Holtzman, S., Meinhold, A., Morris, S.C., Pardi, R., Sun, C., Daniels, J.I., Layton, D., McKone, T.E., and Straume, T., 1993a, Pilot Study Risk Assessment for Selected Problems at the Savannah River Site (SRS), Brookhaven National Laboratory, Upton, N.Y., BNL-48776.

Hamilton, L.D., Meinhold, A., Baxter, S.L., Holtzman, S., Morris, S.C., Pardi, R., 
Rowe, M.D. and Sun, C., 1993b, Pilot Study Risk Assessment for Selected Problems at the Fernald Environmental Management Project (FEMP), Brookhaven National Laboratory, Upton, N.Y., BNL-48777

Hamilton, L.D., Holtzman,S., Meinhold, A.F., Morris, S.C., Roive, M.D., Daniels, J.I., Layton, D.W., and Anspaugh, L.R., 1993c, Lessons Lizarned: Needs for Improving Human Health Risk Assessment at USDOE Sites, (Prepared for Office of Environmental Restoration and Waste Management, Office of Technology Development, United States Department of Energy), Brookhaven National Laboratory, Upton, NY

Holden, C., 1993, No excess cancer seen from bomb tests. Science 262: 1976. IAEA, 1989. Evaluating the Reliability of Predictions Made Using Environmental Transfer Models, Safety Series No. 100, International Atomic Energy Agency, Vienna.

Israeli, M., and Nelson, C.B., 1992, Distribution and expected time of residence for U.S. households. Risk Analysis 12: 65-72.

Layton, D.W., Anspaugh, L.R., Bogen, K.T., and Straume, T., 1993, "Risk Assessment of Soil-Based Exposures to Plutonium at Experimental Sites Located on the Nevada Test Site and Adjoining Areas," in Pilot Study Risk Assessment for Selected Problems at the Nevada Test Site (NTS), J.I. Daniels, Ed., Lawrence Livermore National Laboratory, Livermore, CA, UCRL-LR-113891, pp. 19-67.

Mallon, B., Bainer, R.W., Qualheim B., and lovenitti J., 1991, Investigations of tritiated water in the vadose zone from a leak in an underground tank. Abstracts with Programs. -Annual Meeting, San Diego, California, October 21 24, 1991. The Geological Society of America, Boulder, Co, pg A24 (abstr. \#25169).

Mckone, T.E., 1990, Dermal uptake of organic chemicals from a soil matrix. Risk Analysis 10: 407-419.

McKone, T.E., and Daniels, J.I., 1991, Estimating human exposure through multiple pathways from air, water, and soil. Regulat. Toxicol. Pharmacol. 13: 36-61.

Meinhold, A.F., Hamilton, L.D., Holtzman, S., and Baxter, S.L., 1993. Human Health Risk Assessment for Radium Discharged in Produced Waters Offshore. Phase II.

Morris, S.C., and Meinhold, A.F., 1988. Report of Technical Support for the Hazardous Waste Remedial Action Program on Health and Environmental Risks of Inactive Hazardous Waste Sites, Brookhaven National Laboratory, Upton, N.Y., BNL-42339.

Morris, S.C., Rowe, M.D., Holtzman, S., and Meinhold, A.F., 1992, Review of Technical Justification of Assumptions and Methods Used by the Environmental Protection Agency for Estimating Risks Avoided by Implementing MCLs for Radionuclides, Informal Report, Brookhaven National Laboratory, Upton, N.Y., BNL-48482.

Morgan, M.G., and Henrion, M.,1990. Uncertainty. A Guide to Dealing with Uncertainty in Quantitative Risk and Policy Analysis, Cambridge University Press, NY. 
National Research Council, 1983, Risk Assessment in the Federal Government: Managing the Process, Committee on the Institutional Means for Assessment of Risks to Public Health, Commission on Life Sciences, NRC, National Academy Press, Washington, D.C.

NCRP, 1984, Radiological Assessment: Predictirig the Transport, Bioaccumulation and Uptake by Man of Radionuclides Released to the Environment, NCRP Report No. 76, National Council on Radiation Protection and Measurements, Bethesda, MD

Rish, W.R., 1988, Approach to Uncertainty in Risk Analysis, ORNLTM-10746, Oak Ridge National Laboratory, Oak Ridge, TN.

Shevenell, L., and Hoffman, F.O., 1993, Necessity of uncertainty analyses in risk assessment. J. Hazard. Materials 35: 369-385.

Shiraishi, K., Muramatsu, Y., Nakajima, T., Yamamoto, M., Los, I.P., Kamarikov, I.Y., and Buzinny, M.G., 1992, Radionuclide contents in environmental samples as related to the Chernobyl accident. J. Radioanalyt. Nuclear Chem., Articles, 171: 319-328.

Shlyakhter, A., 1993, Improved framework for uncertainty analysis: accounting for unsuspected errors. C/F-MPM-II-02, Final Program and Abstracts, Annual Meeting, Society for Risk Analysis, McLean, VA.

Shlyakhter, A.I., and Kammem, D.M., 1993a, Uncertainties in modeling low probability/ high consequence events: application to population projections and models of sea-level rise. Proceedings Second InternationalSymposium on Uncertainty Modeling and Analysis, pp246-253, IEEE Computer Society Press, Los Alamitos, CA.

Shlyakhter, A., Shlyakhter, I., Broido, C., and Wilson, R., 1993b, Estimating uncertainty in physical measurements, observational and environmental studies: lessons from trends in nuclear data. ProceedingsSecond InternationalSymposium on Uncertainty Modeling and Analysis, pp310-317, IEEE Computer Society Press, Los Alamitos, CA.

Slob, W., 1993, A simple and quick method for uncertainty analysis in multiplicative models. D-WAM-08, Final Program and Abstracts, Annual Meeting, Society for Risk Analysis, McLean, VA.

Stone, R.C., 1993, Scientists study 'cold war' fallout. Science 262: 1968.

Taylor, A.C., 1993, Using objective and subjective information to develop distributions for probabilistic exposure assessment. J. Expos. Anal. Environ. Epidemiol. 3: 285-298.

U.S. Department of Commerce, 1988, American Housing Survey for the United States, 1985, Current Housing Reports (H-150-85, 28-29), U.S. Department of Commerce, Bureau of Census; and U.S. Department of Housing and Urban Development.

U.S. Department of Commerce, 1989, American Housing Survey for the United States, 1987, Current Housing Reports (H-150-87, 52-53), U.S. Department of Commerce, Bureau of Census; and U.S. Department of Housing and Urban Development.

USEPA, 1989a, Risk Assessment Guidance for Superfund, Vol. 1. Human Health Evaluation Manual (Part A), Iterim Final, EPA540/1-89/002, Office of Emergency and Remedial Response, United States Environmental Protection Agency, Washington, D.C. 
USEPA, 1989b, Assessing Human Health Risks from Chemically Contaminated Fish and Shellfish: A Guidance Manual, EPA/503-8-89-002, Office of Marine and Estuarine Protection (WH-5.58F) and Office of Water Regulation and Standards (WH-552), United States Environmental Protection Agency, Washington, D.C.

USEPA, 1991a, Guidance for Risk ,4ssessment, Risk Assessment Council, United States Environmental Protection Agency, Washington, D.C.

USEPA, 1991b, An SAB Report: Fadionuclides in Drinking Water, EPA-SABRAC-91-009, Science Advisory Board (A-101), Report by the Drinking Water Subcommittee, Radiation Advisory Committee, United States Environmental Protection Agency, Washington, D.C.

USEPA, 1991C, 40CFR Parts 141 and 142. National primary drinking water regulations; radionuclides; proposed rule, Fed. Regist., 56: 33050-33127. USEPA, 1992a, Guidlines for exposure assessment; Notice. Fed. Regist., Part VI, 57: 22888-22938.

USEPA, 1992b, Inventory of Exposure-Related Data Systems Sponsored by Federal Agencies, EPAV600/R-92/078, Office of Health Research, Washington, D.C. (Prepared by Eastern Research Group, Inc., Lexington, MA). 


\section{Appendix 1}

\section{Summary of the Workshop on Uncertainties Associated With Assessments of Health Risks at U.S. Department of Energy Facilities (August 4, 1993)}

Leonard D. Hamilton, Seymour Holtzman, Anne F. Meinhold, Samuel C. Morris, and Michael D. Rowe

Biomedical and Environmental Assessment Group, Division

Department of Applied Science, Brookhaven National Laboratory, Upton, New York

Table of Contents

Abstract. 


\begin{abstract}
The Biomidical and Environmental Assessment Group at Brookhaven National Laborator: hosted a workshop on August 4, 1993. The purpose of the workshop was to determine the major uncertainties associated with risk assessments at U.S. Department of Energy Facilities, and to explore methods for describing and reducing these uncertainties. Sources of uncertainty were identified, and categorized as to their site-specific, regional, national or universal nature. There was general agreement that a screening level assessment should be performed to identify the important uncertainties that contribute most to the distribution of risk, and there is a need identify independent parameters. Analytical methods were suggested to accomplish these goals.
\end{abstract}


HAMILTON, Leonard D. (Host)

BARI, Robert A.

BARRY, Timothy

BAUM, John W.

DANIELS, Jeffrey I.

DRAUGHN, Robert

EVANS, John S.

GINZBURG, Dr. Lev

HENRION, Max

\section{Participants}

Head, Biomedical and Environmental Assessment Group Building 490D Brookhaven National Laboratory Upton, NY 11973-5000

Deputy Department Chairman Dept. of Advanced Technology

Bldg. 197C

Brookhaven National Laboratory Upton, NY 11973-5000

PM 223X

Chief, Science Policy Staff/ORME

U. S. Environmental Protection Agency $401 \mathrm{M}$ Street, S. W.

Washington, DC 20460

Head, Radiological Sciences Division Dept. of Advanced Technology Bldg. 703M

Brookhaven National Laboratory Upton, NY 11973-5000

Health and Ecological Assessment Division Geosciences and Environmental Research Program Physics Department

P. O. Box 808, L-453

Lawrence Livermore National Laboratory Livermore, CA 94551-9900

Chairman, Dept. of Material Sciences Medical University of South Carolina 171 Ashley Avenue Charleston, SC 29425-2641

Department of Environmental Health Sciences Harvard School of Public Health 665 Huntington Avenue Boston, MA 02115 President Applied Biomathematics, Inc. 100 North Country Road Setauket, NY 11733

Lumina Decision Systems Suite 390 350 Cambridge Avenue Palo Alto, CA 94306 
HOEL, David

HOLTZMAN, Seymour

JONES, R. Martin

LAZARETH, Otto W.

MEINHOLD, Anne F.

MORRIS, Dr. Samuel C.

MOSKOWITZ, Paul D.

NEWBERRY, W. Marcus
Chairman

Department of Biometry and Epidemiology

Medical University of South Carolina

171 Ashley Avenue

Charleston, SC 29425-8017

Scientist

Biomedical and Environmental

Assessment Group

Building 490D

Brookhaven National Laboratory

Upton, NY 11973-5000

Director

Medical University of South Carolina

171 Ashley Avenue

Charleston, SC 29425

Building 701

Brookhaven National Laboratory

Upton, NY 11973-5000

Environmental Science Assoc.

Biomedical and Environmental

Assessment Group

Building 490D

Brookhaven National Laboratory

Upton, NY 11973-5000

Scientist

Biomedical and Environmental

Assessment Group

Building 490D

Brookhaven National Laboratory

Upton, NY 11973-5000

\section{Scientist}

Biomedical and Environmental

Assessment Group

Building 490D

Brookhaven National Laboratory

Upton, NY 11973-5000

Vice President and Provost of Academics

Medical University of South Carolina

$200 \mathrm{H}$ Administration/Library

Charleston, SC 29425 
NOVACK, Steven D.

SCHMIDT, Michael

SMALL, Mitchell J.

TALCOTT, Frederick W.

WALLO, Andrew, III
MS 3850

EG\&G Idaho

Idaho National Engincering Laboratory

P. O. Box 1625

Idaho Falls, ID 83414

\author{
Assistant Professor \\ Microbiology and Immunology \\ Medical University of South Carolina \\ 201 Basic Science Building \\ Charleston, SC 29425 \\ Civil Engineering and \\ Engineering Public Policy \\ Carnegie Mellon University \\ Pittsburgh, PA 15213
}

PM 220

Ollice of Policy, Planning and Evaluation

U. S. Environmental Protection Agency $401 \mathrm{M}$ Street, S. W.

Washington, DC 20460

EH-232, GA-098/FORS

U. S. Department of Energy

1000 Independence Avenue, S. W.

Washington, DC 20585 


\section{AGENDA}

QUANTIFICATION AND REDUCTION OF UNCERTAINTIES IN HUMAN HEALTH RISK ASSESSMENTS AT USDOE FACILITIES

\section{WEDNESDAY, AUGUST 4,1993}

9:00 - 9:30 a.m.

Workshop Objectives

L.D. Hamilton

9:30 - 10:00 a.m.

BNL/LLNL Pilot Study and

L.D. Hamilton

10:00 - 10:30 a.m.

Realistic Risk Assessment

Uncertainties in the Hanford Dose

M. Henrion

Reconstruction Project

$10: 30$ - 11:30 a.m.

Definition of Terms:

Uncertainty and Uncertainty Analysis

$11: 30-12: 30$ p.m.

Identification of Major Uncertainties in Risk Assessment at USDOE Facilities

S.C. Morris

S. Holtzman

12:30 - 1:30 p.m.

Lunch

1:30 - 2:30 p.m.

Why Monte Carlo Methods are Obsolete

L. Ginsburg

2:30 - 4:30 p.m.

Quantification, Analysis, and

S.C. Morris Approach to Reduction of Uncertainties 


\section{SUMMARY OF THE WORKSHOP}

Introduction - Leonard Hamilton

Risk assessments at USDOE facilities are hampered by a number of uncertainties. Some of these uncertainties are inherent to the analysis of risk while others arise from a lack of knowledge or data. The objectives of the workshop included:

(1) Exploration of methods to identify the most important uncertainties in risk assessment for USDOE facilities to guide USDOE research efforts;

(2) Identification of other factors that should guide USDOE research priorities; and

(3) Suggesting approaches to reducing important uncertainties through additional research.

In his introductory remarks, Dr. Hamilton stated the purpose of the meeting to be an informal exchange of information and concepts needed for identifying and quantifying uncertainties. Decisions concerning cleanup goals, choices among cleanup technologies, and funding prioritization should be largely risk-based. Risk assessments will be used more extensively by the U.S. Department of Energy (USDOE) in the future. USDOE needs to define risk assessment methods and fund research to reduce major sources of uncertainty in risk assessments at USDOE facilities.

Health Effects are the greatest concern, although social and economic considerations are also important. Current methods for assessing health risks, based on regulatory issues, are overly conservative, causing unnecessary public concern and misallocation of funds for remediation. Conservatism of the assessments arises from the interactions of single values (usually high; e.g., the upper $95 \%$ confidence limit value) in worst case scenarios (e.g., the maximally exposed individual).

Dr. Hamilton presented an overview of the assessments made in a pilot study of problems at three USDOE sites:

(1) The Savannah River Site (SRS - Hamilton et al., 1993a);

(2) The Fernald Environmental Management Project (FEMP - Hamilton et al., 1993b); and

(3) The Nevada Test Site (NTS - Daniels et al., 1993; Layton et al., 1993).

The assessments were a collaborative effort of the Biomedical and Environmental Assessment Group (BEAG) at Brookhaven National Laboratory (BNL) and the Health and Ecological Assessment Division (HEAD) at Lawrence Livermore National Laboratory (LLNL). In response to a question from Mitchell Small, the BEAG participants emphatically stated that the assessments addressed both uncertainty and variability.

The Pilot Study demonstrates a realistic and objective approach to risk assessment, using distributions of parameter values, and uncertainty bounds on the distributions, to obtain probabilistic health risks. The definition of a realistic and objective risk assessment is one that: 
(1) Avoids unrealistic and conservative exposure scenarios by focusing on reasonable and sensible scenarios;

(2) Replaces generic or inappropriate default assumptions with site-specilic data or assumptions;

(3) Characterizes uncertainties in parameters explicitly, and does not depend on conservative assumptions;

(4) Uses site-specific transport and exposure models, and depends on monitoring data for model calibration or input parameters;

(5) Uses the latest scientific information in describing dose-response relationships;

(6) Acknowledges that situations with very little data available to describe source terms or exposure routes cannot be assessed in a realistic way without additional data collection. These situations can be addressed credibly and practically in screening level assessments.

(7) Addresses and distinguishes between uncertainty and variability.

Uncertainty Analysis and the Hanford Environmental Dose Reconstruction Project (HEDR) - Max Henrion

The purpose of this project is to estimate the radiation dose to individuals, since 1944, from radionuclides at DOE's Hanford Site, near Richland, WA. Iodine-131 releases in the 1940s and 1950s are a special concern. The work is performed for the Centers for Disease Control by the Battelle Pacific Northwest Laboratories, under the supervision of an 18-person Technical Steering Panel (TSP). An Uncertainty and Sensitivity Analysis Plan was developed to help the TSP decide the appropriate methods to treat uncertainty by:

(1) Quantifying the likelihood that the dose is in a given interval; and

(2) Determining which parameters have the largest impact on the uncertainty in predictions.

The plan includes the following recommendations:

(1) All dose predictions in the HEDR project should contain a description of the uncertainty, to be estimated only with a Monte Carlo (Latin Hypercube Sampling) approach;

(2) Use commercially available Monte Carlo software to estimate uncertainty for representative cases, and apply by analogy to others that use a deterministic model;

(2) Uncertainties in predicted doses should be presented graphically, using box plots;

(3) All mathematical models should be subjected to hierarchical sensitivity analysis, using multiple regression where possible (otherwise subsets of parameters should be held constant to evaluate uncertainties); 
(4) Do sensitivity analysis for a selection of representative locations and individuals.

The HEDR Review Pancl recommended a plan for uncertainty analysis.

(1) Clearly define the assessment questions and relate the $n$ to epidemiological requirements in terms of population exposed and duration of exposure.

(2) Distinguish between uncertainty and variability (and uncertainty about variability).

(3) Employ formal probability elicitation methods to obtain expert opinion on key uncertain parameters.

(4) Consider dependence and correlations between input parameters. Assess and model them where important.

(7) Use Latin Hypercube sampling and rank order linear regression methods for uncertainty and sensitivity analysis.

(8) Estimate uncertainty due to sampling.

(9) Where linear significance ( $R$-square) is low, use conditional variance analysis to examine sensitivities.

(10) Use scatter plots to help identify important parameters and non-linear relationships.

Presentation of results should be tailored for three audiences:

(1) Educated lay people (means and $90 \%$ subjective confidence intervals);

(2) Scientists and analysts (Tukey box plots); and

(3) Specialists in uncertainty analysis (probability density functions and cumulative distributions).

Results of sensitivity analysis should be shown to all audiences. A comprehensive uncertainty analysis should be $15 \%$ to $30 \%$ of the overall cost of modeling and analysis. If done right, uncertainty analysis can reduce the total cost, or produce a more accurate result with given resources. At the start of the analysis, major uncertainties should be identified in a screening assessment.

\section{Definition of Terms: Uncertainty and Uncertainty Analysis - Samuel C. Morris}

This discussion was presented as a lexicon containing definitions of uncertainty related-issues from different viewpoints (Table 1). Although various sources present apparently different definitions and classification schemes for factors affecting the quality of risk estimates, much of the difference is merely choices of words. In some cases, different sources present opposite definitions of the same words (e.g., "uncertainty" and "variability" in Morgan and Henrion, 1990 and USEPA, 1992a). Some of this confusion arises from historical uses of terms from other contexts that are conflicting when combined in the same context. 
Table 1. List of issues that have to be addressed in quantification of uncertainties.

\begin{tabular}{|c|c|c|}
\hline CLASSIFICATION OF UNCERTAINTY & \multicolumn{2}{|c|}{ CAUSE OF UNCERTAINTY } \\
\hline & $\begin{array}{c}\text { Variability } \\
\text { (Ifelerogencily) }\end{array}$ & Errors, lack of knowledge \\
\hline \multicolumn{3}{|l|}{ IAEA Safety Series No. 100, 1989} \\
\hline Specification of problems (scenarios) & $\begin{array}{l}\text { Conceptual models, } \\
\text { qualitative alternatives }\end{array}$ & $\begin{array}{l}\text { Simplification, lack of } \\
\text { knowledge }\end{array}$ \\
\hline Formulation of conceptual models & $\begin{array}{l}\text { Distributions in time and } \\
\text { space }\end{array}$ & $\begin{array}{l}\text { Simplification, lack of } \\
\text { knowledge }\end{array}$ \\
\hline Formulation of computational models & & $\begin{array}{l}\text { Simplification, lack of } \\
\text { knowledge }\end{array}$ \\
\hline Estimation of parameter values & $\begin{array}{l}\text { Distributions in quantity, } \\
\text { rate, time and space }\end{array}$ & $\begin{array}{l}\text { Measurement error, } \\
\text { measurement bias, }\end{array}$ \\
\hline Calculation and documentation & & $\begin{array}{l}\text { Procedural error, lack of } \\
\text { clarity }\end{array}$ \\
\hline Type A uncertainty & $\begin{array}{l}\text { Distributions in lime and } \\
\text { space }\end{array}$ & \\
\hline Type B uncertainty & & Lack of knowledge \\
\hline \multicolumn{3}{|l|}{ Morgan and Henrion, 1990} \\
\hline Random error and statistical variation & & Measurement error \\
\hline Systematic error & & Measurement bias \\
\hline Linguistic imprecision & & Lack of clarity \\
\hline Variability & $\begin{array}{l}\text { Distributions in quantity, } \\
\text { rate, time and space }\end{array}$ & \\
\hline Randomness and unpredictability & $\begin{array}{l}\text { Distributions in quantity, } \\
\text { rate, time and space }\end{array}$ & \\
\hline Disagreement & & $\begin{array}{l}\text { Interpretations of } \\
\text { available data }\end{array}$ \\
\hline Approximations & & $\begin{array}{l}\text { Simplification, lack of } \\
\text { knowledge }\end{array}$ \\
\hline Model form & & $\begin{array}{l}\text { Simplification, lack of } \\
\text { knowledge }\end{array}$ \\
\hline \multicolumn{3}{|l|}{ EPA Exposure Assessment Guidelines, 1992a } \\
\hline Scenario uncertainty & & Errors, lack of knowledge \\
\hline Parameter uncertainty & $\begin{array}{l}\text { Distributions in quantity, } \\
\text { rate, time and space }\end{array}$ & $\begin{array}{l}\text { Measurement error, } \\
\text { measurement bias, lack of } \\
\text { knowledge }\end{array}$ \\
\hline Model uncertainty & & $\begin{array}{l}\text { Simplification, lack of } \\
\text { knowledge }\end{array}$ \\
\hline Variability & $\begin{array}{l}\text { Distributions in quantity, } \\
\text { rate, time and space }\end{array}$ & \\
\hline Uncertainty & & Lack of knowledge \\
\hline
\end{tabular}


The workshop generally agreed that the uncertainty associated with final risk estimates produced by a Monte Carlo analysis has two components.

(1) Uncertainty caused by lac $k$ of knowledge or errors. This includes uncertainty in the description of the dosa response function for a contaminant, as well as measurement and modeling errors. Scientific uncertainty includes random or systematic error, linguistic imprecision (both in description and specifications), disagreement, and modei uncertainty (approximations and lack of understanding of mechanisms). This uncertainty is typically reduced by using measurement data.

(2) Natural variability or heterogeneity consists of the differences among individuals (including physical characteristics such as body weight, and behavior such as residence time) or of natural processes (e.g., weather patterns or stream flows). Measurement or modelling errors contribute to the uncertainty associated with the description of natural variability.

Uncertainty associated with variability can be reduced by disaggregation of components. For example, selection of a particularly susceptible fraction of a human population reduces uncertainty associated with variability of the entire population to uncertainty associated with the lesser variability of a population subset. Variability affects the mean of a distribution, but not the tail (where the "sensitive population" is represented). John Evans suggested that when a specific fractile is mentioned as the sensitive part of a population, the numerator describing the entire population should also be specified.

\section{Identification of Major Uncertainties in Risk Assessment at USDOE Facilities -} Seymour Holtzman

\section{Source Terms}

The source term description in risk assessment is a major candidate for reducing uncertainty by increases in quality and quantity of data (hetter definition). The Pilot Study illustrates this point. The uncertainty of source term data was high for groundwater concentrations of radionuclides at the Nevada Test Site because of scarcity of data (Daniels et al., 1993). In contrast, the data for tritium releases from the Savannah River Site to the Savannah River were of high quality, allowing the construction of an empirical model for predictive risk assessment (Hamilton et al., 1993a). Obviously, the quality and quantity of source term data are site specific, depending on the capability of each facility to monitor and measure its pollutant emissions.

Emissions of pollutants at DOE sites tend to be either well quantified, because they are long-standing problems that have received much study, or poorly quantified because they are new or have been ignored in the past as unimportant. There is little middle ground. Sources of uncertainty for emissions of pollutants include:

(1) Chemical or physical form of emission;

(2) Probability distribution of amounts emitted (routine, accidents); annual average emissions;

(3) Time distribution of emissions with respect to other important variables, such as transport conditions (e.g., weather) or locations and activities of exposed persons (e.g., day-night); 
(4) Locations of emissions with respect to local transport mechanisms (e.g., streams, intervening topography);

(5) Effect of lo:al conditions on amounts or form of emissions (e.g.. weather, facility operations)

(6) Estimation models, assumptions, and approximations.

All of these sources of uncertainty are specific to individual DOE sites, and all can be reduced by improved information. Uniform methods are available for collecting and evaluating the necessary information, but the specific information to be collected will differ for each site. Irreducible natural variability, such as that attributable to weather and outcomes of random processes, can be quantified as frequency or probability distributions.

If new data-collection activities are started in support of risk assessments, some care must be taken that the kinds of information produced are useful for the intended purpose. Producers of the data may think, for example, that more is hetter, and produce reams of unanalyzed numbers from which it is difficult to extract useful generalizations, or they may produce much data of one kind without supporting data of another kind with which to generalize the results (e.g., concentrations of air pollutants near a source, without measurements of weather). Consumers of the data should ensure that the producers understand the kind of information required and design sampling strategies appropriately.

\section{Scenarios}

Scenarios establish the conditions to be analyzed in a risk assessment. Which scenarios are most likely for predictive assessments? Scenario uncertainty arises in predictions of:

(1) Institutional control and future land use of a facility;

(2) Demography and changes in populations associated with a specific facility or region; and

(3) Future receptor locations in the region of a facility.

Even analyzing current conditions leaves much to analysts' discretion. Sources of uncertainty related to selection of scenarios for analysis include:

(1) Assumptions about future values or distributions of parameters (e.g., land use, population density, weather);

(2) Decisions about probabilities and extremes of conditions to be included (e.g., levels of regulation, permitted activities, loss of institutional control, physical extremes, such as accidents, storms, earth quakes);

(3) Time horizon, discount rate.

Assumptions are needed only for the extremes of conditions (routine, accidents, current weather distribution, average weather, worst weather, etc.) to be included for developing scenarios used to estimate existing risks. The level of information required is generally available for any DOE site.

Estimation becomes increasingly difficult, and increasingly uncertain, as the time 
horizon is extended into the future. The assessment at the Savannah River Site is an example in which important demographic information for the next 10 years was obtained or confirmed by contacting local utility companies (Hamilton et al., 1993a). Reasonable predictions of development and land use can be made from locally available information for frerhaps 20 years, and highly uncertain predictions can be made for 20 additional years. Beyond that, all is conjecture, and little to be gained by attempting to include details. The only reasonable level of detail for risk assessments far in the future is a "semi-worst-case scenario" for a single person living at the site under believable future conditions. No attempt should be made to estimate total population risk far into the future; results of such an estimate are so uncertain as to be meaningless for planning decisions.

\section{Media and Transport}

The uncertainties in media and transport of pollutants are related to problems that range from site- and regional-specific to universal (e.g., chemistry of pollutants - can we identify classes of important radionuclides based on chemical behavior?). The parameters and models developed for emissions and plumes from specific facilities are site- and regional-specific problems. They include problems related to descriptions of:

(1) Soil characteristics - porosity and nature of soils (binding of pollutants), resuspension of soils, uptake from or deposition of soils on plants;

(2) Air - wind direction and velocity, chemical and physical interactions;

(3) Ground water - chemistry and chemistry-dependent hydrogeology; flow rates;

(4) Surface water - chemistry, hydrogeology, flow rates, sediments;

(5) Fond chains - bioaccumulation in edible portions of animals and plants that are affected by the facility.

Sources of uncertainty that are related to pollution dispersion, transformation, and transport include:

(1) Partitioning among media (air, water, land) and within components of media (e.g., food chains, deposition); chemical or physical transformations during transport; selection of important media for analysis;

(2) Values or distributions of physical constants (e.g., dispersion coefficients, chemical transformations);

(3) Seasonal distributions (e.g., weather, water flow);

(3) Outdoor-indoor relationships;

(4) Estimation models, assumptions, and approximations.

These sources of uncertainty tend to be more general among DOE sites in that estimation methods are based on a limited range of available transport models for water, air, and land. The detailed conceptual models, data, and assumptions needed to exercise 
these models are site-specific. Some DOE sites already have complex, highly detailed transport models supported by large amounts of site-specific data (e.g., ground-water flow models). Even the highest-quality transport models, however, have uncertainties of a factor of two or more.

\section{Exposure Pathways}

A sensitivity analysis to determine the dominant exposure pathways must be done early in the assessment process. Early sensitivity analysis will benefit the assessment in that it increases the efficiency of the overall risk assessment by concentrating on the pathways of exposure that significantly contribute to the risk.

Exposure pathways are the last stage of transport modeling. They include those parts of the transport directly related to the behavior and characteristics of those at risk. Uncertainty related to exposure include:

(1) Temporal and spatial distributions of population density;

(2) Intake rates (breathing, eating, drinking, immersion); significant local demographic characteristics (e.g., age distribution, activity rates, time indoors and outdoors);

(3) Local differences in intake rates (e.g., consumption of local produce and fishes);

(4) Estimation models, assumptions, and approximations.

Exposure estimates are affected by uncertainties in pathway exposure factors (PEFs). Pathway exposure factors are terms that translate unit concentrations in media (e.g., $\mathrm{pCi} / \mathrm{L}$ ) into exposures per unit time (e.g., $\mathrm{pCi} / \mathrm{yr})$. PEFs use information on human physiology and behavior, and environmental transport for specific media (McKone, 1990). These uncertainties arise from biological and behavioral variations, as well as the accuracy and precision of estimated distributions for each parameter. Many of the characteristics important to personal exposure are constant, or have a near-constant distribution nationwide (e.g., breathing rates). Others, such as intake of local foods can be significantly different, depending on local production and exports. National data are readily available to all; local data are usually available somewhere, but are not necessarily easily found by DOE site personnel.

Exposure pathways include PEFs that are:

(1) Outdoor - time spent outdoors (may be age and job related), inhalation (including resuspended material), ingestion (soil), dermal (swimming, partial body contact, transfer rates);

(2) Indoor - time spent indoors (may be age and job related), workplace (inhalation, ingestion, dermal contact), home (inhalation in shower, bathroom or house); digestion (food, water, pica), dermal (bathing, washing, transfer rates)

PEFs provide examples of correlated parameters, especially those that are age- or weight-related. Time spent indoors or outdoors varies depending on age and work. Thus adults and babies are expected to spend less time outdoors than other cohorts. Exceptions are adults whose employment is of an outdoor nature (e.g., farmers, professional athletes and recreational employees, military, various utility workers). 
Inhalations of materials outdoors and indoors vary with breathing rates, age, weight, surface area of the body, and degree of physical activity at work. Breathing rates are related to age, weight, surface area, and degree of physical activity.

Ingestion rates for food and water generally vary with age and weight. However, ingestion of specific food items can also show a regional variation that is of significance for assessments at USDOE facilities. Ingestion of material outdoors can occur by bringing soiled hands into contact with the mouth, or, in the case of children, willful ingestion of contaminated soil (pica). These modes of ingestion can also apply indoors, as do ingestion of contaminated food and water at home or at work. Indoor pica behavior in children can expose them to contaminated particles of paint that contain adherent pollutants from aerial deposition.

Exposure by dermal contact in both outdoor and indoor scenarios can vary from partial to whole-body immersion during swimming, recreational, occupational, and bathing or washing. Exposure by dermal contact is probably more significant for organic and lipid-soluble materials than for most inorganic molecules, because of the lipid composition of the dermal layer of the skin. Thus, dermal exposure is related to transfer rates, as measured by such factors as partition coefficients. Transfer rates can vary with the location of the body surface that is exposed during partial dermal contact. Dermal exposure is also generally related to surface area of the skin and age.

Although there are published or available national or regional data bases for many of the PEF, there may be no organization, statistical analyses or summaries that are appropriate for risk assessment. The best use of a national database often requires reanalysis for appropriate regions, age-weighting techniques where age-related information is available, and for selection of groups or populations that are most susceptible to the effects of a specific pollutant.

Commercial software packages are available for statistical analyses of the data bases, and determinations of appropriate distributions of the data. For example, a simple logprobability plot can be used to determine whether data is normally or lognormally distributed. In some cases, the choice of a lognormal distribution may be based on logical considerations.

Overall uncertainty about a parameter may result from a combination of uncertainty and variability. In cases where there are insufficient data, the choice of a distribution requires judgment and is of greater uncertainty. This can happen when the lower and upper extreme values of a parameter are known, but intermediary sampling is insufficient. One might choose to say that there is an equal chance for any value between the extremes (a uniform distribution), or select an intermediary value as a mode (a triangular distribution). Alternatively, commercial Monte Carlo software allows one to set up a custom distribution in which calculation samples are selected in proportion to the frequency of the available measured values for a specific parameter.

Choice of the distribution type and its contribution to the uncertainty of the risk assessment should be fully explained for all significant parameters.

\section{Dose Response and Risk Factors}

Dose response and risk factors are major sources of uncertainty for a variety of reasons. The responses or endpoints are associated with carcinogenesis, noncarcinogenic toxicity, or reproduction and teratogenesis. Uncertainty arises from variations in susceptibility among humans (or test animals). A major uncertainty arises from an 
inability to define the nature of dose response curves at low doses. Risk (or slope) factors published by regulatory agencies (e.g., USEPA, 1991) are derived by interacting combinations of conservative values for parameters with multiplicative safety functions. These interactive features serve a risk management, rather than a risk assessment, function by producing risk factors with protective margins for public health. Although there may be some expression of uncertainty for the regulatory risk factors, it is difficult to sort out the contributions of individual parameters because of the complexity of the interactions. Nevertheless, it may be possible to adjust some risk factors to reduce uncertainty by expressing them as distributions that more closely reflect probability of risk (Meinhold et al., unpublished; Morris et al., 1993a, b).

Dose-response functions for pollutants other than radionuclides are among the most uncertain portions of risk assessments. Data are usually available for research animals, at exposures many times higher than those to which humans are exposed. In many cases, therefore, we have the least information about what we care about most. Sources of uncertainty related to dose-response functions include:

(1) Extrapolation of research results from animals at high doses and dose rates to humans;

(2) Extrapolation of research results from humans at high doses and dose rates to others at low doses and dose rates;

(3) Inclusion of only one response (e.g. death) for pollutants with many health and environmental impacts;

(4) Effects of confounding factors (e.g., smoking and cancer);

(5) Estimation of doses to affected tissues per unit exposure;

(6) Effects of natural variability in responses among humans;

(7) Estimation models, assumptions, and approximations.

Many of the dose-response relationships in the literature have been derived in support of regulation and risk management, and therefore include significant "margins of safety" that make them inappropriate for realistic risk assessments. More research on responses at low dose levels is essential to reducing uncertainties. Health effects of radiation, in particular, is a DOE responsibility.

\section{Why Monte Carlo Methods are Obsolete - Lev Ginsburg}

In spite of the title, this presentation was not an attack on Monte Carlo methods per $s e$. The presentation was primarily concerned with the uncertainties generated by interactions and assumed independence of parameters during Monte Carlo analyses.

For correlated parameters, a default assumption of independence of parameters in a risk assessment yields the same central tendencies in a distribution resulting from mathematical operations between the parameters. Uncertainties can be over- or underestimated because use of the default assumption may not yield true extremes. For 
example, when two distributions are added together $(A+B)$ and then averaged, the result will be the same as that achieved by adding the average of distribution $A$ to the average of distribution B. This does not hold true for other percentiles. It is common to express the variance of a distribution as the value of the $95^{\text {th }}$ percentile of probability. Addition of two independent $95^{\text {th }}$ percentile values produces a sum that is more conservative because its real probability is 0.9975 , rather than 0.95 .

Interactions between correlated parameters can either underestimate or overestimate the variances and extremes of the distribution (uncertainties) of the results, depending on the nature of the mathematical operations (Ferson and Long, unpublished). Ferson and Long described a method of dependency bounds analysis for determining the variability and bounds of distributions resulting from mathematical operations between correlated parameters. It was generally agreed that this method might be a useful tool for sensitivity analysis when independence between parameters must be examined closely. Conquest (1993) also recently described simple methods for dealing with correlated parameters.

\section{Quantification and Analysis - Sam Morris}

The workshop participants, listed important broad areas of uncertainty in risk analysis. This was followed by general discussion of analytical approaches in each topic.

(1) Value of information is an important issue. Some of the most valuable information may be globally applicable and does not require further refinement. In contrast, expending resources to derive the dose response for a chemical present at many USDOE sites may be more important and useful than obtaining a specific hydrological parameter for a particular site. The importance of establishing contributions of parameters by investigating ranges of uncertainties (range-finding analysis) at the beginning of every risk assessment was reemphasized. There is a need to establish some measure of scale, and to find out which parameters are shared or not shared by USDOE sites. A book by Morgan and Henrion (1990) contains information and references on rank-order linear regression as a tool for sensitivity analysis.

For correlated parameters, John Evans and others suggested that we may need empirical data to recalibrate a distribution range or confidence interval that has been projected.

(2) There is an overall question of adequate knowledge to reduce uncertainties and their related costs. A minimal state of knowledge is required to do uncertainty analysis, particularly knowledge of the structure of a problem. First level screening models are useful.

(3) There are concerns about correlated parameters in an assessment. Usually, the major contributors to uncertainty are limited to a few parameters. Therefore they will be amenable to an analysis of correlation (multivariate analysis).

Lev Ginsburg suggested fuzzy set theory, as opposed to probabilities, as a possible approach for looking at possible outcomes, when distributions of parameters are not well characterized. Max Henrion stated that fuzzy set theory was best for control applications, not predictive applications.

(4) The role of unforeseen circumstances (surprise) was discussed, with a question about the duration of an unlikely event. Does such an event create a larger variance? 
Max Henrion said that statistical approaches, such as Bayesian techniques and secondary uncertainty analysis, are available to investigate this question. Mitchell Small

demonstrated how to go from Monte Carlo analysis to Bayesian parameter estimates (Brand and Small, unpublished; Patawadham and Small, 1992; Small and Escobar, 19!)3). Conquest's (1993) recent description of using the Bayesian approach in graphical form is particularly relevant to the question of upper and lower boundary estimates.

(5) There is a question about time prospects in predictive risk assessment. How does one know when to quit? An ecological risk level for a long-term future going out to 10,000 years is useless. Andrew Wallo questioned the value of such a long-term prediction for health risks. Background populations cannot be determined that far into the future. 


\section{References}

Conque:t, L.D., 1993. Statistical approaches to environmental monitoring: Did we teacl, the wrong things? Environ. Monitor. Asssess. 26: 107-124.

Daniels, J.I., R. Andricevic, L.R. Anspaugh, and R.L. Jacobson, 1993, "Risk-Based Screening Analysis of Ground Water Contaminated by Radionuclides Introduced at the Nevada Test Site (NTS)," in Pilot Study Risk Assessment for Selected Problems at the Nevada Test Site (NTS), J.I. Daniels, Ed., Lawrence Livermore National Laboratory, Livermore, CA, UCRL-LR-113891, pp. 69-97.

Hamilton, L.D., S. Holtzman, A. Meinhold, S.C. Morris, R. Pardi, C. Sun, J.I. Daniels, D. Layton, T.E. McKone and T. Straume, 1993a, Pilot Study Risk Assessment for Selected Problems at the Savannah River Site (SRS), Brookhaven National Laboratory, Upton, N.Y., BNL-48776.

Hamilton, L.D., A. Meinhold, S.L. Baxter, S. Holtzman, S.C. Morris, R. Pardi, M.D. Rowe and C. Sun, 1993b, Pilot Study Risk Assessment for Selected Problems at the Fernald Environmental Management Project (FEMP), Brookhaven National Laboratory, Upton, N.Y., BNL-48777.

IAEA, 1989. Evaluating the Reliability of Predictions Made Using Environmental Transfer Models. International Atomic Energy Agency, Safety Series No. 100, Vienna.

Layton, D.W., L.R. Anspaugh, K.T. Bogen, and T. Straume, 1993, "Risk Assessment of Soil-Based Exposures to Plutonium at Experimental Sites Located on the Nevada Test Site and Adjoining Areas," in Pilot Study Risk Assessment for Selected Problems at the Nevada Test Site (NTS), J.I. Daniels, Ed., Lawrence Livermore National Laboratory, Livermore, CA, UCRL-LR-113891, pp. 19-67.

McKone, T.E., 1990, Dermal uptake of organic chemicals from a soil matrix. Risk Analysis 10: $407-419$.

Morgan, M.G., and M. Henrion, 1990. Uncertainty. A Guide to Dealing with Uncertainty in Quantitative Risk and Policy Analysis. Cambridge University Press, NY.

Morris, S.C., M.D. Rowe, S. Holtzman and A.F. Meinhold, 1993. Review of Technical Justification of Assumptions and Methods Used by the Environmental Protection Agency for Estimating Risks Avoided by Implementing MCLs for Radionuclides. Informal Report, BNL-48482 (Prepared for Office of Environmental Guidance, U.S. Department of Energy).

Morris, S.C., M.D. Rowe, S. Holtzman and A.F. Meinhold, 1993, National Radiation Exposures and Risks caused by Implementing EPA's Proposed National Primary Drinking Water Regulations (Prepared for Office of Environmental Guidance, U.S. Department of Energy).

Patwardham, A. and M.J. Small, 1992. Bayesian methods for model uncertainty analysis with application to future seal level rise. Risk Analysis 12: 513-523.

Rish, W.R., 1988. Approach to Uncertainty in Risk Analysis. ORNL/TM-10746, Oak Ridge National Laboratory (Prepared for the Office of Radiation Programs, U.S. Environmental Protection Agency).

Small, M.J., and M.D. Escobar, 1993. Discussion. in C. Gatsonis, J.S. Hodges, R.E. Kass, and N.D. Sinpurwalla (eds.), Case Studies in Bayesian Statistics. Lecture Notes in Statistics, Vol. 83, Springer-Verlag, NY.

USEPA, 1991. Health Effects Assessment Summary Tables, Annual FY-1991, OERR 9200.6-303 (91-1), United States Environmental Protection Agency, Washington, D.C.

USEPA, 1992a, Guidelines for Exposure Assessment; Notice. Fed. Regist. 57: 2288822937. 